\section{(A) Check for updates}

Cite this: Food Funct., 2022, 13, 3760

\title{
Melatonin induces fat browning by transdifferentiation of white adipocytes and de novo differentiation of mesenchymal stem cells $\uparrow$
}

\author{
Diego Salagre, (D) a Meriem Chayah, ${ }^{a}$ Antonio Molina-Carballo, ${ }^{* b}$ \\ María-Jesús Oliveras-López, ${ }^{c}$ Antonio Munoz-Hoyos, ${ }^{\text {b }}$ Miguel Navarro-Alarcón, (iD d \\ Gumersindo Fernández-Vázquez ${ }^{\mathrm{e}}$ and Ahmad Agil (iD *a
}

\begin{abstract}
The role of melatonin in obesity control is extensively accepted, but its mechanism of action is still unclear. Previously we demonstrated that chronic oral melatonin acts as a brown-fat inducer, driving subcutaneous white adipose tissue (sWAT) into a brown-fat-like function (beige) in obese diabetic rats. However, immunofluorescence characterization of beige depots in SWAT and whether melatonin is a beige-fat inducer by de novo differentiation and/or transdifferentiation of white adipocytes are still undefined. Lean (ZL) and diabetic fatty (ZDF) Zücker rats were subdivided into two groups, control (C) and oral melatonin-supplemented ( $M, 10 \mathrm{mg} \mathrm{kg}^{-1}$ day $^{-1}$ ) for 6 weeks. Mesenchymal stem cells (MSCs) were isolated from both rat inguinal fat and human lipoaspirates followed by adipogenesis assays with or without melatonin (50 nM for $12 \mathrm{~h}$ in a $24 \mathrm{~h}$ period, $12 \mathrm{~h}+/ 12 \mathrm{~h}-$ ) mimicking the light/dark cycle. Immunofluorescence and western-blot assays showed the partial transdifferentiation of white adipocytes in both ZL and ZDF rats, with increasing thermogenic and beige markers, UCP1 and CITED1 and decreasing white adipocyte marker ASC-1 expression. In addition, melatonin increased UCP1, CITED1, and PGC1$\alpha$ expression in differentiated adipocytes in both rats and humans. These results demonstrate that melatonin increases brown fat in obese diabetic rats by both adipocyte transdifferentiation and de novo differentiation. Furthermore, it promotes beige MSC adipogenesis in humans. This may contribute to the control of body weight attributed to melatonin and its metabolic benefits in human diabesity.
\end{abstract}

Received 22nd December 2021 Accepted 27th February 2022

DOI: $10.1039 / \mathrm{d} 1$ fo04360a

rsc.li/food-function and oxidative stress. ${ }^{2}$ The modern lifestyle enhances obesity and overweight through a large energy imbalance caused by a higher caloric intake with lack of physical activity. ${ }^{3}$ The latest studies from the World Health Organization revealed that the global prevalence of obesity has tripled between 1975 and 2016. ${ }^{4}$ In 2016, more than 1.9 billion adults aged 18 years and over were overweight ( $39 \%$; body mass index $\geq 25 \mathrm{~kg} \mathrm{~m}^{-2}$ ) and 650 million of them were obese $(13 \%$; body mass index $\geq 30 \mathrm{~kg}$ $\mathrm{m}^{-2}$ ). In the same year, 340 million children and adolescents between the ages of 5 and 19, and another 41 million under the age of 5 , were obese or overweight, also raising a growing concern about childhood obesity. Obesity in humans and other mammals leads to the storage of excess energy as triglycerides in adipose tissue. While white adipose tissue (WAT) functions as a lipid storage reservoir, brown adipose tissue (BAT) provides a mechanism for thermogenesis, dissipating energy in the form of heat. ${ }^{5}$ Brown-colored adipocytes have also been found within WAT. They are called beige or brite (brown on white) adipocytes. Interestingly, these beige/brite cells resemble white adipocytes in the basal state, but respond to thermogenic stimuli with higher levels of thermogenic 
genes and higher respiration rates. Furthermore, beige/brite cells have a different gene expression pattern than white or brown fat cells. ${ }^{6}$ While the alanine-serine-cysteine transporter1 (ASC-1) is highly expressed in WAT with little or no expression in thermogenic adipose tissues such as BAT, suggesting that this transporter is a specific surface marker for $\mathrm{WAT}^{7,8}$ the $\mathrm{Cbp} / \mathrm{The}$ transactivator that interacts with $\mathrm{p} 300$ with the Glu/Asp-rich carboxy-terminal domain 1 (CITED1) is a marker selectively expressed in beige adipocytes of uncoupling protein 1 (UCP1) positive in mice, as well as in humans. ${ }^{9-12}$

Melatonin is a hormone produced at night by the pineal gland $^{13,14}$ and also in many other tissues. ${ }^{15,16}$ In addition to physiological circadian rhythm regulation, melatonin has antioxidant, anti-inflammatory, and anti-obesogenic effects. Melatonin is a powerful antioxidant, and its presence in numerous plants and foods has been described as beneficial for human and animal health. ${ }^{17,18}$ Melatonin limits obesity in rodents without influencing food intake $\mathrm{e}^{19-23}$ with inconsistent changes in locomotor activity, either increase, ${ }^{19,23}$ decrease $\mathrm{d}^{24}$ or no changes. ${ }^{21}$ Moreover, in this same rat strain, we have shown that melatonin does not affect locomotor activity. ${ }^{25}$ Furthermore, in this same rat strain, we have shown that chronic melatonin supplementation has an antidiabetic effect accompanied by an improvement of insulin resistance, as evidenced by a lower HOMA-IR index ${ }^{26}$ and increases systemic levels of adiponectin which improves insulin sensitivity by increasing energy expenditure and fatty acid oxidation through the activation of AMP activated protein kinase (AMPK) and by increasing the expression of PPAR $\gamma$ target genes ${ }^{27}$ like PGC1 $\alpha$, the master regulator of the thermogenic program and mitochondrial biogenesis, and UCP1 its molecular effector. ${ }^{28}$ This suggests that melatonin may act as a thermogenic agent. In fact, many previous reports indicated that melatonin enhances the growth and function of thermogenic adipose tissue. ${ }^{29}$ In addition, white subcutaneous fat contains patches of beige adipocytes, in both animals and humans. ${ }^{9,30}$ These fat cells have structural and functional properties similar to brown adipocytes. ${ }^{31,32}$ Beige deposits can be induced in animals and humans by physiological stimuli, such as cold exposure, which increases adrenergic tone, ${ }^{31,33}$ and by physical activity through irisin, a myokine recently identified in animals and humans. ${ }^{32}$ This discovery is of utmost interest since the search for safe and effective thermogenic agents is a promising strategy to fight obesity. Therefore, melatonin, besides stimulating the growth and thermogenic activity of thermogenic adipose tissue, could have an "irisin-like" effect by inducing the appearance of "brown-like" adipocytes in areas of WAT. In this sense, a study of our group has shown that the chronic oral administration of melatonin induces the appearance of "brown-like" adipocyte nests in the subcutaneous inguinal WAT from ZDF rats. ${ }^{25}$ Moreover, we have observed a basal inguinal thermogenic activity and a cold-induced sensitizing regional action in response to the systemic administration of melatonin. The current epidemic of obesity has increased the interest in studying adipocyte formation (adipogenesis), especially in beige/brite adipocytes, as they could shed light on the search for new effective treatments. ${ }^{34,35}$ Numerous lineage experiments provide evidence that adrenergic stimulation and/ or cold exposure increase beige adipocyte biogenesis (browning) in WAT by de novo differentiation of pre-adipocyte cells found in WAT depots (adipogenesis), and/or reversible transdifferentiation of mature white adipocytes whose commitment reversibly changes to a beige phenotype, leading to the direct differentiation of mature white to beige adipocytes. ${ }^{6,36-44}$ Several studies also revealed that melatonin and other hormonal factors like triiodothyronine (T3), parathyroid hormone (PTH), glucagon-like peptide 1 (GLP1), leptin and natriuretic peptides also induce the browning of WAT and/or BAT thermogenesis stimulation. ${ }^{45}$ A recent transcriptional and epigenomic study showed specific expression patterns in beige adipocytes from mice, suggesting a distinct lineage and an epigenomic memory of prior cold exposure for beige adipocytes. ${ }^{46}$ These pieces of evidence may support the hypothesis that beige adipocytes contribute to adipose tissue plasticity and adjusting their gene expression patterns and morphology, depending on the presence and frequency of different stimuli, ${ }^{39,41}$ for a rapid thermogenic response. ${ }^{46}$

In the present study, we investigated the characterization of beige depots in sWAT in ZDF rats and the elucidation of whether melatonin induces beige adipocytes by the differentiation of ZDF rat and human subcutaneous WAT-derived mesenchymal stem cells (MSC) and/or the trans-differentiation of white adipocytes to beige ones in ZDF inguinal fat.

\section{Materials and methods}

\subsection{Animals and experimental protocols}

This study was carried out in accordance with the European Union guidelines for animal care and protection and the Ethical Committee of the University of Granada (Granada, Spain). The permit project number is 4-09-2016-CEEA. Male ZDF rats (fa/fa $n=16$ ) and male lean littermates (ZL, fa/- $n=$ 16) were obtained at the age of 5 weeks. Animals were maintained on Purina 5008 rat chow (protein 23\%, fat 6.5\%, carbohydrates $58.5 \%$, fiber $4 \%$, and ash $8 \%$; Charles River, France) and housed 2 per clear plastic cage in a climate-controlled room at $28-30{ }^{\circ} \mathrm{C}$ and $30-40 \%$ relative humidity, with a $12 \mathrm{~h}$ dark/light cycle (lights on at 7 a.m.). In the first week after arrival, the animals were acclimated to room conditions, and the water intake was recorded. Then, both $\mathrm{ZL}$ and $\mathrm{ZDF}$ rats were subdivided into four groups. Animals were supplemented for 6 weeks either with melatonin in drinking water (melatonin-supplemented, M-ZDF, $n=8$ and M-ZL, $n=8$ ) or the vehicle (controls, C-ZDF, $n=8$ and C-ZL, $n=8$ ). Melatonin was dissolved in a minimum volume of absolute ethanol and diluted in drinking water to yield a dose of $10 \mathrm{mg}$ per $\mathrm{kg}$ body weight (BW) per day, with a final concentration of $0.066 \%$ $(\mathrm{w} / \mathrm{v})$ ethanol. Water intake and $\mathrm{BW}$ were recorded twice weekly. Fresh melatonin and vehicle solutions were prepared twice a week, and the melatonin dose was adjusted to the BW throughout the study period. Water bottles were covered with 
aluminum foil to protect from light. At the end of the supplementation period, the animals were anesthetized with sodium thiobarbital (thiopental) and sacrificed.

\subsection{Immunofluorescence}

Inguinal adipose tissue from Zücker rats was fixed by immersion in $10 \%$ formaldehyde for $12 \mathrm{~h}$ and after dehydration by immersion in increasing concentrations of ethanol (70-100\%), they were included in paraffin forming blocks. Paraffinembedded inguinal adipose tissue from Zücker rats was cut into $7 \mu \mathrm{m}$ sections. Before staining, the cuts were deparaffinized with xylene and decreased concentrations of ethanol (100-70\% and water). They were subjected to citrate-based antigen retrieval using Antigen Retrieval Citra Solution (Biogenex) and blocked for $1 \mathrm{~h}$ at room temperature with rabbit polyclonal antibodies. The sections were incubated for $1 \mathrm{~h}$ at room temperature with a mouse monoclonal antibody against CITED1 at a dilution of 1:1000 (Sigma, Spain) or a rabbit monoclonal antibody against UCP1 at a dilution of $1: 1000$ (Sigma, Spain) or immunoglobulin G (IgG) as a negative control. Secondary detection was performed for $1 \mathrm{~h}$ at room temperature using anti-mouse Fluorescein isothiocyanate (FITC) and anti-rabbit Cyanine 3 (Су3) (Invitrogen, Carlsbad, CA, USA). The cuts were labeled with 4',6-diamidino2-phenylindole (DAPI). Images were captured using an Olympus IX2 microscopy. Image analysis and quantification was carried out by measuring signal intensities using the ImageJ programmer.

\subsection{Isolation of mesenchymal stem cells}

Adipose tissue samples ( 300 mg) from Zücker rats were excised from brown-like (beige) and white fat regions of the inguinal fat pad and washed in PBS with $1 \%(\mathrm{w} / \mathrm{v})$ antibiotics (penicillin-streptomycin (P/S), Sigma, Spain). MSCs from beige (bMSCs) and white (WMSCs) inguinal adipose tissue were isolated by enzymatic digestion (Collagenase type I, Sigma, Spain) at $37^{\circ} \mathrm{C}$ for $1 \mathrm{~h}$. The enzymatic solution was inactivated by adding complete Dulbecco's Modified Eagle's Medium (DMEM, Gibco, Life Technologies, Spain) supplemented with $10 \%$ Fetal Bovine Serum (FBS) and 1\% P/S. The mixture was centrifuged at $400 \mathrm{G}$ for $10 \mathrm{~min}$ and the pellet was resuspended in growth medium (complete DMEM supplemented with L-glutamine $2 \mathrm{mM}, 10 \% \mathrm{FBS}, 1 \% \mathrm{P} / \mathrm{S}$ and $1 \%$ doxycycline).

Human MSCs were isolated from lipoaspirates' adipose tissue. Human abdominal fat was obtained from healthy donors $(n=8)$ undergoing liposuction plastic surgery (range of age 44-61). All samples used in this study were collected with informed consent and Institutional Review Board approval (ethic permission number: 02/022010 Hospital Virgen de la Victoria, Málaga, Spain). Briefly, lipoaspirates were washed and treated for $1 \mathrm{~h}$ at $37{ }^{\circ} \mathrm{C}$ with $1 \%$ collagenase type IA (Sigma Aldrich, Spain) in Hank's Balanced Salt Solution (Sigma Aldrich, Spain) under gentle agitation. The digested tissue was centrifuged, and the supernatant discarded. The cell pellet obtained was washed twice in DMEM supplemented with 10\% FBS and resuspended in growth medium. Approximately $1.8 \times 105$ (range $1.6-2 \times 105$ ) cells were obtained from $1 \mathrm{~g}$ of lipoaspirate.

\subsection{Cell culture}

MSCs from inguinal adipose tissue of Zücker rats and human lipoaspirates were seeded and expanded in the appropriate sterile plastic flask at equal densities $\left(5 \times 103\right.$ cells per $\left.\mathrm{cm}^{2}\right)$ in T-75 culture flasks with $10 \mathrm{ml}$ of complete culture medium consisting of DMEM (Gibco, Life Technologies, Spain) supplemented with L-glutamine ( $2 \mathrm{mM}), 10 \%$ FBS (Gibco, Life Technologies, Spain), 1\% P/S (Gibco, Life Technologies, Spain) and $1 \%$ doxycycline (Sigma, Spain) and cultured in an incubator at $37{ }^{\circ} \mathrm{C}$ with a humidified atmosphere containing $21 \% \mathrm{O}_{2}$ and $5 \% \mathrm{CO}_{2}$. The cell culture medium was replaced twice a week. Freshly isolated cells were grown in monolayer culture up to passage $4-5$ at a seeding density of $5 \times 103$ cells per $\mathrm{cm}^{2}$ at each passage.

\subsection{MSC characterization}

After two passages, MSC specific surface markers were analyzed by flow cytometry with non-conjugated antibodies and in vitro differentiation assay to be characterized. Mouse antirat/human CD-73 (1:100; BD, Pharmingen, San Jose, CA, USA), mouse anti-rat/human CD-90 (1:100; BD, Pharmigen, San Jose, CA, USA), mouse anti-rat/human CD-105 (1:100; BD, Pharmigen, San Jose, CA, USA), mouse anti-rat/human CD-29 ( $1: 100$; BD, Pharmingen, San Jose, CA, USA), mouse anti-rat anti-SCA-1 (1:100; BD, Pharmingen, San Jose, CA, USA), mouse anti-rat CD-133 (1:100; BD, Pharmingen, San Jose, CA, USA), mouse anti-rat/human CD-45 (1:100; Millipore, Burlington, MA, USA) and mouse anti-rat/human CD-34 ( $1: 100$; BD, Pharmigen, San Jose, CA, USA) were used. As a secondary antibody, bovine anti-mouse FITC (fluorescein isothiocyanate, green fluorescence, Santa Cruz Biotechnology Inc., Santa Cruz, CA, USA) was used for all samples. Isotype control could not be carried out because all the primary antibodies were produced in mice. As negative controls, cell aliquots were incubated only with isotype-matched mouse IgG conjugated to FITC (Santa Cruz Biotechnology Inc., Santa Cruz, CA, USA) under the same conditions. To carry out this procedure, cultured cells in a T-175 flask were washed with PBS and detached by incubation with trypsin diluted $1: 1$ in PBS. After trypsin inactivation with complete medium and centrifugation at $1500 \mathrm{rpm}$ for $5 \mathrm{~min}$, pellets were resuspended with $10 \mathrm{ml}$ of Blocking Buffer, which contains $2-4 \%$ of bovine serum albumin (BSA) and $2 \mu \mathrm{M}$ ethylenediaminetetraacetic acid (EDTA) in PBS. During $1 \mathrm{~h}$ incubation at $37^{\circ} \mathrm{C}$, this solution blocked nonspecific binding between the antibody and other regions. Then, $6 \mathrm{ml}$ of the resuspension was distributed into 6 cytometer tubes, $1 \mathrm{ml}$ in each one. The samples were centrifuged at $1500 \mathrm{rpm}$ for $5 \mathrm{~min}$ and the pellet was resuspended with $90 \mu \mathrm{l}$ of PBS and $10 \mu \mathrm{l}$ of each primary antibody, for the two cell lines, not including the controls. After incubation at $37{ }^{\circ} \mathrm{C}$ for $15-20 \mathrm{~min}$, the samples were washed with $5 \mathrm{ml}$ of PBS by centrifugation at $1500 \mathrm{rpm}$ for $5 \mathrm{~min}$ to elimin- 
ate the antibody excess and reduce false positives and background signal. $10 \mu \mathrm{l}$ of the secondary antibody and $90 \mu \mathrm{l}$ of PBS were added, to each sample, which were then incubated at $37{ }^{\circ} \mathrm{C}$ for 20 min under dark conditions. After that, the samples were washed with $5 \mathrm{ml}$ of PBS by centrifugation at $1500 \mathrm{rpm}$ for $5 \mathrm{~min}$ before being analyzed using a FACScan flow cytometer (BD Biosciences, San Jose, CA, USA).

For the MSC multipotent differentiation potential characterization, in vitro adipogenic, osteogenic, and chondrogenic differentiation assays were performed. MSCs were plated at the density of 300000 cells per well in a three 6-well plate one for each differentiation assay with adipogenic (DMEM, 10\% FBS, $1 \% \mathrm{P} / \mathrm{S}, 1 \mathrm{mM}$ dexamethasone, $500 \mu \mathrm{M}$ isobutyl methylxanthine (IBMX), $60 \mu \mathrm{M}$ indomethacin and $10 \mu \mathrm{g} \mathrm{ml} \mathrm{ml}^{-1}$ insulin), osteogenic (DMEM, 10\% FBS, 1\% P/S, $10 \mathrm{nM}$ dexamethasone, $5 \mathrm{mM} \beta$-glycerophosphate and $50 \mu \mathrm{g} \mathrm{ml}^{-1}$ ascorbic acid) and chondrogenic (DMEM, 10\% FBS, 1\% P/S, 1\% insulin-transferrin-selenium, $100 \mathrm{nM}$ dexamethasone, $40 \mu \mathrm{g}$ $\mathrm{ml}^{-1}$ proline, $10 \mathrm{ng} \mathrm{ml} \mathrm{m}^{-1}$ transforming growth factor-beta 3

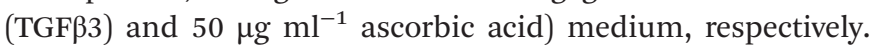
Cells were cultured for 21 days at $37^{\circ} \mathrm{C}$ in a humidified atmosphere containing $21 \% \mathrm{O} 2$ and $5 \% \mathrm{CO}_{2}$, changing the medium twice a week to perform complete MSC differentiation into adipocytes, osteocytes, and chondrocytes. After the in vitro differentiation assay, differentiated cells and MSCs were fixed with $4 \%$ paraformaldehyde (30 min at room temperature), washed twice with PBS, stained with Oil Red O (adipocytes), Alizarin Red (osteocytes) or toluidine (chondrocytes) (30 $\mathrm{min}$ at room temperature) followed by three washes with PBS, and visualized with an optical microscope and photographed.

\subsection{In vitro melatonin treatment}

ZDF rat and human MSCs were subjected to an in vitro melatonin treatment to differentiate them into adipocytes. MSCs were plated at the density of 30000 cells per $\mathrm{cm}^{2}$ in a 12-well plate with pre-adipocyte growth medium (PGM) consisting of DMEM, 10\% FBS and L-glutamine (2 mM) and grown to confluence for 2 days. Cells were then incubated for 10 days in a pre-adipocyte differentiation medium (PDM), to achieve the commitment of cells to the adipogenesis, with or without melatonin. Melatonin was used at $50 \mathrm{nM}$ and was added intermittently in melatonin-treated samples (for $12 \mathrm{~h}$ in a $24 \mathrm{~h}$ period, $12 \mathrm{~h}+/ 12 \mathrm{~h}-$, mimicking the light/dark cycle). The PDM consisted of PGM with $1 \mu \mathrm{M}$ dexamethasone (Sigma, St Louis, MO, USA), $60 \mu \mathrm{M}$ indomethacin (Sigma, Spain), $500 \mu \mathrm{M}$ 3-isobutyl-1-methylxanthine (IBMX, Sigma, Spain) and $0.01 \mathrm{mg}$ $\mathrm{ml}^{-1}$ insulin (Sigma, Spain). Then, the PDM was replaced with an adipogenic differentiation medium (ADM, Lonza, Basel, Switzerland) and cells were incubated 10 days more. Adipogenesis was monitored by the morphological examination of the cellular accumulation of lipid droplets by AdipoRed Assay Reagent (Lonza, Basel, Switzerland) following the manufacturer's protocol. The stained lipid droplets were visualized with an optical microscope and photographed. To quantify adipogenesis, the absorbance of the stained cultures was measured at $520 \mathrm{~nm}$ using a microplate reader.

\subsection{Quantification of UCP1, ASC-1, PGC1 $\alpha$ and CITED1}

ZDF rat and human MSCs and adipocytes obtained after in vitro melatonin treatment were harvested in $10 \mathrm{mM}$ TrisHCL ( $\mathrm{pH}$ 7.5), $150 \mathrm{mM} \mathrm{NaCl,} 2 \mathrm{mM}$ EDTA, 1\% Triton X-100, $10 \%$ glycerol (all from Sigma, Spain) and protease inhibitor cocktail (Thermo Fisher Scientific, Waltham, MA, USA), and placed on ice for $20 \mathrm{~min}$. Following centrifugation $(13000 \mathrm{~g}$, $4{ }^{\circ} \mathrm{C}, 30 \mathrm{~min}$ ), the protein content of the supernatant was determined using Protein Assay Kit II (BioRad, Spain). For inguinal adipose tissue samples from Zücker rats, about $100 \mathrm{mg}$ were homogenized in lysis buffer $(150 \mathrm{mM} \mathrm{NaCl}$, 5 mM EDTA, 50 mM Tris-HCl, pH 7.4) without Triton X-100 and homogenized with a Teflon pestle. The homogenates were centrifuged $\left(3000 \mathrm{~g}, 4^{\circ} \mathrm{C}, 15 \mathrm{~min}\right)$, and the upper-fat layer was removed from the supernatant. Then, Triton X-100 was added to a final concentration of $1 \%$. After incubating at $4{ }^{\circ} \mathrm{C}$ for 30 minutes, extracts were cleared by centrifugation at $15000 \mathrm{~g}$ at $4{ }^{\circ} \mathrm{C}$ for $15 \mathrm{~min}$ and the protein content of the supernatant was determined using Protein Assay Kit II. $100 \mu \mathrm{g}$ of total protein of each sample was analyzed by sodium dodecyl sulfate-polyacrylamide gel electrophoresis (SDS-PAGE). The gels for immunoblot analyses were transferred to a nitrocellulose membrane (BioRad Trans-Blot SD; BioRad Laboratories, Hercules, CA, USA). Blots were reacted with a $1: 2000$ dilution of primary antibodies (anti-UCP1, anti-ASC-1, anti-PGC1 $\alpha$ and anti-CITED1, all produced in rabbit, Sigma, Spain) in blocking solution (PBS, $5 \%$ BSA). The anti- $\beta$-actin antibody generated in mice (Santa Cruz Biotechnology, Santa Cruz, CA, USA) was used as a control. After overnight incubation at $4{ }^{\circ} \mathrm{C}$ with the primary antibody, horseradish peroxidase-conjugated antirabbit and anti-mouse secondary antibody incubation was performed. Immune reactive signals were detected by enhanced chemiluminescence using a Clarity Western ECL Substrate kit (BioRad, Spain). Blots were digitally recorded with Kodak Image Station 4000 PRO and analyzed by image analysis for molecular weight determinations. Fold changes in relative expression were calculated from the signal intensities derived using the ImageJ programmer.

\subsection{Statistical analysis}

All experiments were repeated at least three times. Data are expressed as means \pm SEM. Means were compared between groups using one way-ANOVA, adjusted by Tukey. SPSS, version 22, for Windows (SPSS, Michigan, IL, USA) was used for the data analyses. $P$-Value $<0.05$ was considered statistically significant, and the levels of significance were labeled on the figures as follows: ${ }^{*} P<0.01 ;{ }^{*} P<0.05$; and $\# \# P<0.01 ; \# P<0.05$.

\section{Results}

3.1 In vivo melatonin supplementation induces partial white to beige adipocyte transdifferentiation in the inguinal WAT of obese diabetic (ZDF) rat

In order to immunocharacterize beige depots, we carried out an immunofluorescence study of inguinal WAT on ZDF and ZL 
rats, supplemented either with melatonin (M-ZDF and M-ZL) or the vehicle (controls, C-ZDF and C-ZL). DAPI blue fluorescence (Fig. 1A) showed a decreased number of cells in the inguinal WAT from ZDF rats compared to lean littermates, with a higher relative cell number in the M-ZDF group compared to the C-ZDF one (C-ZL, $1.046 \pm 0.066$; C-ZDF, $0.102 \pm$
0.019; M-ZDF, $0.488 \pm 0.044 ; \quad P<0.01 ; \quad$ Fig. 1B). Immunofluorescence assay showed a significant decrease in the fluorescence signal of all measured markers in the C-ZDF group which is reversed by in vivo melatonin supplementation in ZDF rats (Fig. $1 \mathrm{C}$ and E). Also, no differences between C-ZL and M-ZL groups were observed in none of the markers deter-

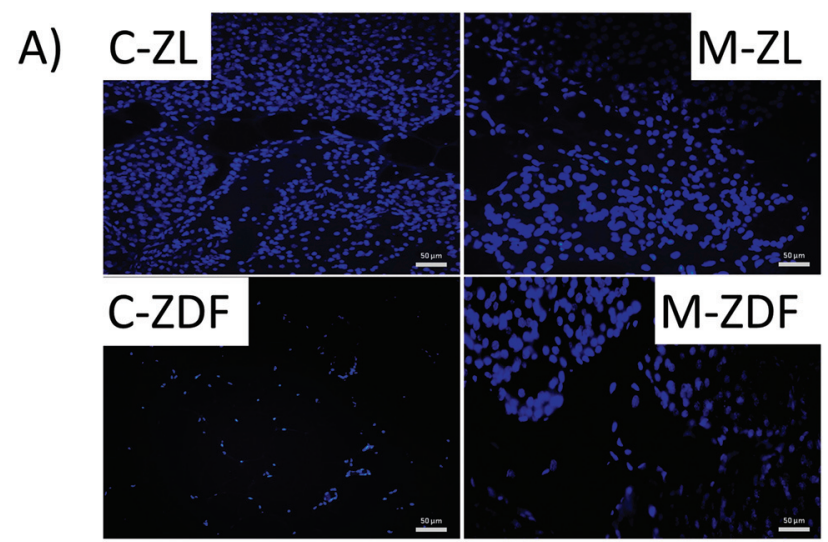

B)

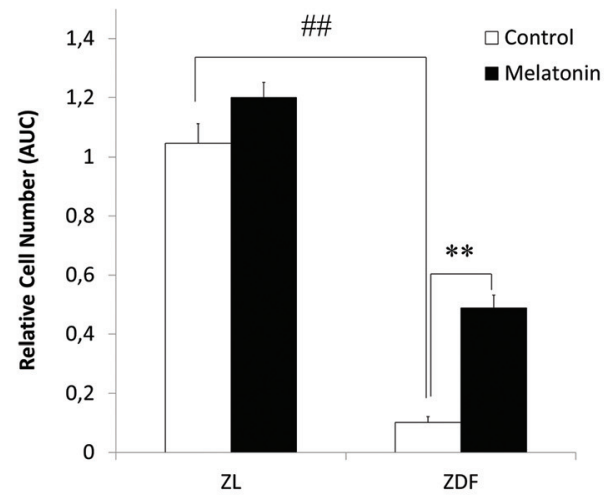

C)

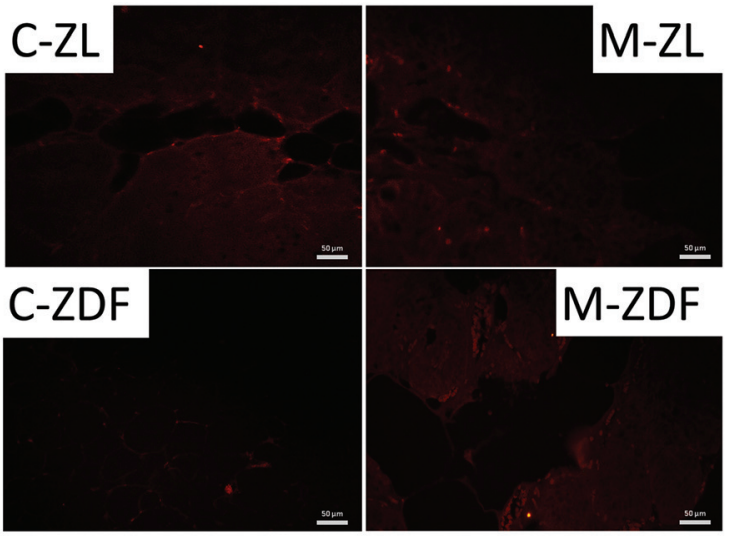

D)
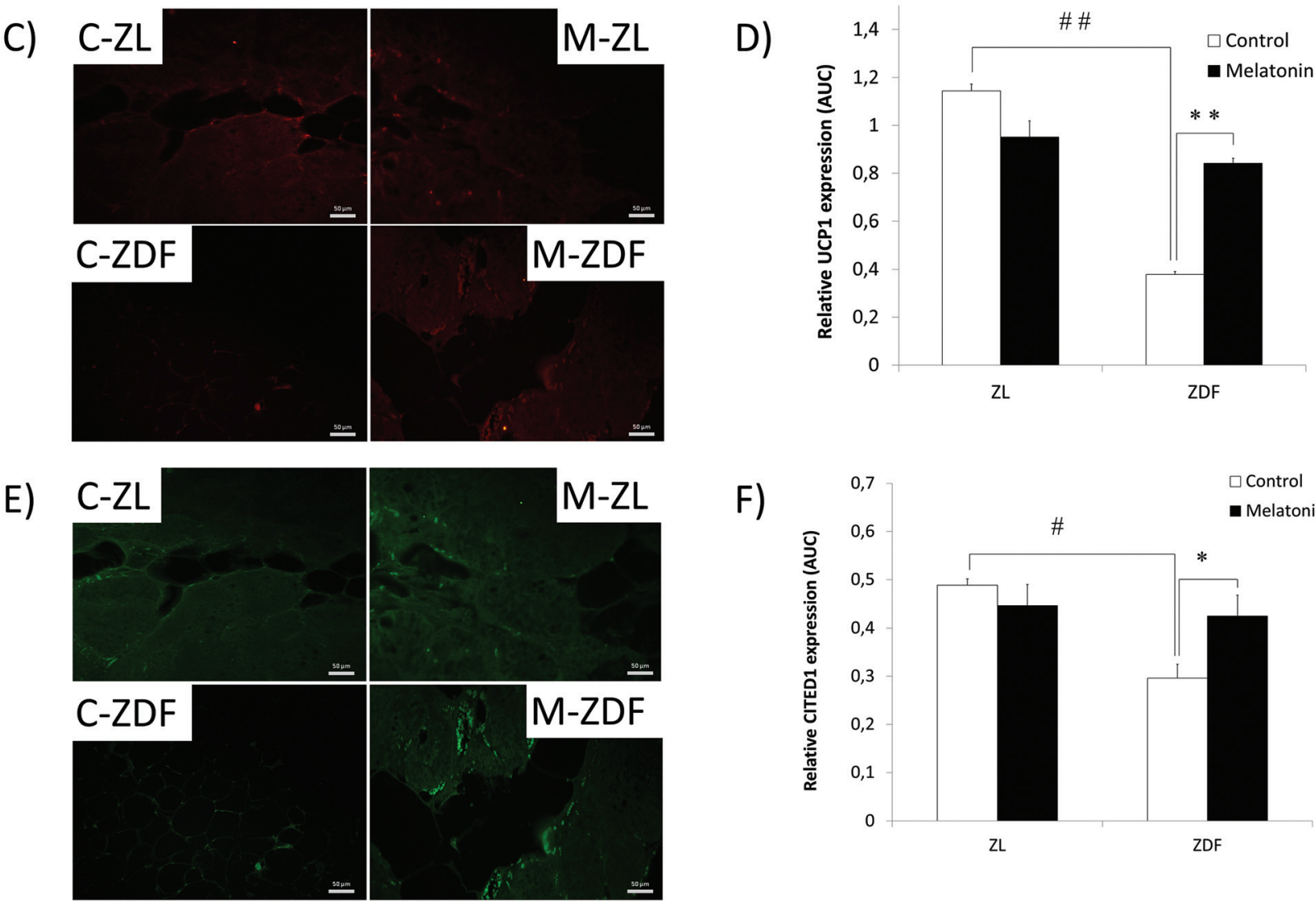

F)

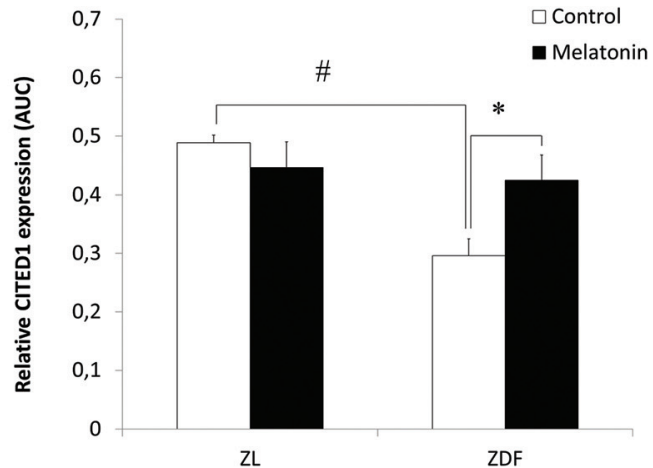

Fig. 1 Immunofluorescence characterization of the "brown-like" cell nests of the melatonin-induced inguinal WAT of the Zücker rats. (A) Representative microscopy image showing blue labeled nucleus (DAPI); (B) quantitative analysis of relative nucleus number corresponding to adipocyte cell number quantification; (C) representative microscopy image showing immunofluorescence in red corresponding to anti-rabbit-monoclonal-UCP1 (Cy3) thermogenic marker; (D) quantitative analysis of the relative expression of thermogenic cell marker UCP1; (E) representative microscopy image showing immunofluorescence in green corresponding to the anti-mouse-monoclonal-CITED1 (FITC) specific beige-cell marker; and (F) quantitative analysis of the relative expression of specific beige-cell marker CITED1. ZL, Zücker lean rats; ZDF, Zücker diabetic fatty rats; C, control-unsupplemented; $M$, melatonin-supplemented. Magnification 20x. Scale bar $50 \mu \mathrm{m}$. All values are expressed as mean $\pm \mathrm{SEM}$ of four independent experiments in triplicate. ${ }^{*} P<0.01 ;{ }^{*} P<0.05 ; \# \# P<0,01 ; \# P<0,05$. 
mined by immunofluorescence. In vivo melatonin supplementation induces higher UCP1 expression in the inguinal WAT from ZDF rats (C-ZDF, $0.378 \pm 0.013$; M-ZDF, $0.842 \pm 0.020 ; P<$ 0.01 ; Fig. 1D). Furthermore, unsupplemented C-ZDF rats slightly expressed UCP1 and not C-ZL the UCP1 expression of which was higher $(\mathrm{C}-\mathrm{ZDF}, 0.378 \pm 0.013$; C-ZL, $1.144 \pm 0.028 ; P$ $<0.01$; Fig. 1D). CITED1 expression in unsupplemented obese rats was lower than that in unsupplemented lean littermates too (C-ZDF, $0.296 \pm 0.029 ; \mathrm{C}-\mathrm{ZL}, 0.489 \pm 0.013 ; P<0.05$; Fig. $1 \mathrm{~F}$ ). In vivo melatonin supplementation also significantly induces CITED1 expression in the inguinal WAT from ZDF rats compared to the corresponding control (C-ZDF, $0.296 \pm 0.029$; M-ZDF, $0.425 \pm 0.042 ; P<0.05$; Fig. 1F). No differences between M-ZDF and C-ZL groups were found, recovering the decreased expression of CITED1 observed in C-ZDF rats. Moreover, to evaluate whether melatonin induces the transdifferentiation of white to beige adipocytes and/or differentiation of MSCs to mature beige adipocytes, white adipocyte quantification in inguinal WAT, UCP1 expression study in MSCs from in vivo studies of both lean and obese non-supplemented and melatonin-supplemented rats, and an in vitro melatonin treatment study of MSCs from the inguinal fat of Zücker rats were accomplished.

For white adipocyte quantification, the expression of ASC-1, a specific cell surface marker, was measured. Western blot analysis revealed that in vivo melatonin supplementation decreases the expression of ASC-1 both in lean (C-ZL, $2.276 \pm$ $0.011 ; \mathrm{M}-\mathrm{ZL}, 1.488 \pm 0.041 ; P<0.01)$ and diabetic fatty rats (C-ZDF, $2.702 \pm 0.079 ; \mathrm{M}-\mathrm{ZDF}, 2.025 \pm 0.026 ; P<0.01)$ as shown in Fig. 2. These results could explain the origin of mela-
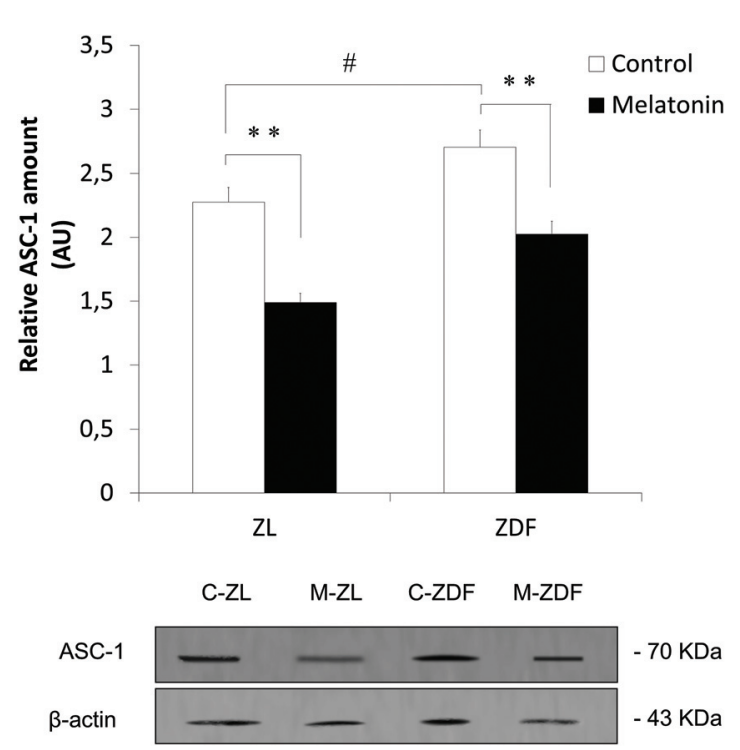

Fig. 2 Effects of in vivo melatonin supplementation on specific white adipocyte marker ASC-1 expression in inguinal adipose tissue from Zücker rats. ZL, Zücker lean rats; ZDF, Zücker diabetic fatty rats; C, control unsupplemented; $M$, melatonin-supplemented. All values are expressed as mean \pm SEM of three independent experiments in duplicate. ${ }^{* *} P<0.01 ; \# P<0.05$. tonin-induced beige adipocytes by partial transdifferentiation of white to beige adipocytes. However, more studies are needed to understand this biological process. Also, ASC-1 expression in non-supplemented obese rats is significantly higher than that in control lean ones (C-ZL, $2.276 \pm 0.011$; C-ZDF, $2.702 \pm 0.079 ; P<0.05$; Fig. 2).

\subsection{In vivo melatonin supplementation effects on UCP1 expression in Zücker rat MSCs}

MSCs of inguinal WAT from in vivo melatonin-supplemented Zücker rats were isolated to study the effect of melatonin in the commitment of MSCs to the brown-like thermogenic adipocyte lineage. As shown in Fig. 3, a significantly increased UCP1 expression was measured by western blot after in vivo melatonin supplementation in MSCs from both lean (C-ZL, $1.241 \pm 0.035 ; \mathrm{M}-\mathrm{ZL}, 1.592 \pm 0.102 ; P<0.05)$ and diabetic fatty rats $(\mathrm{C}-\mathrm{ZDF}, 0.761 \pm 0.022 ; \mathrm{M}-\mathrm{ZDF}, 1.230 \pm 0.154 ; P<0.01)$ compared to their respective controls, with no differences in UCP1 expression between MSCs from obese melatonin-supplemented rats and lean control ones. In addition, MSCs from unsupplemented obese rats showed less UCP1 expression levels than samples from unsupplemented lean rats (C-ZL, $1.241 \pm 0.035$; C-ZDF, $0.761 \pm 0.022 ; P<0.01$; Fig. 3 ) showing the effect of obesity in the UCP1 expression of MSCs.

\subsection{Characterization of MSCs isolated from inguinal fat of Zücker rats and human lipoaspirates}

MSCs were isolated from the inguinal fat pad of Zücker rats and human lipoaspirates. Flow cytometry was carried out to
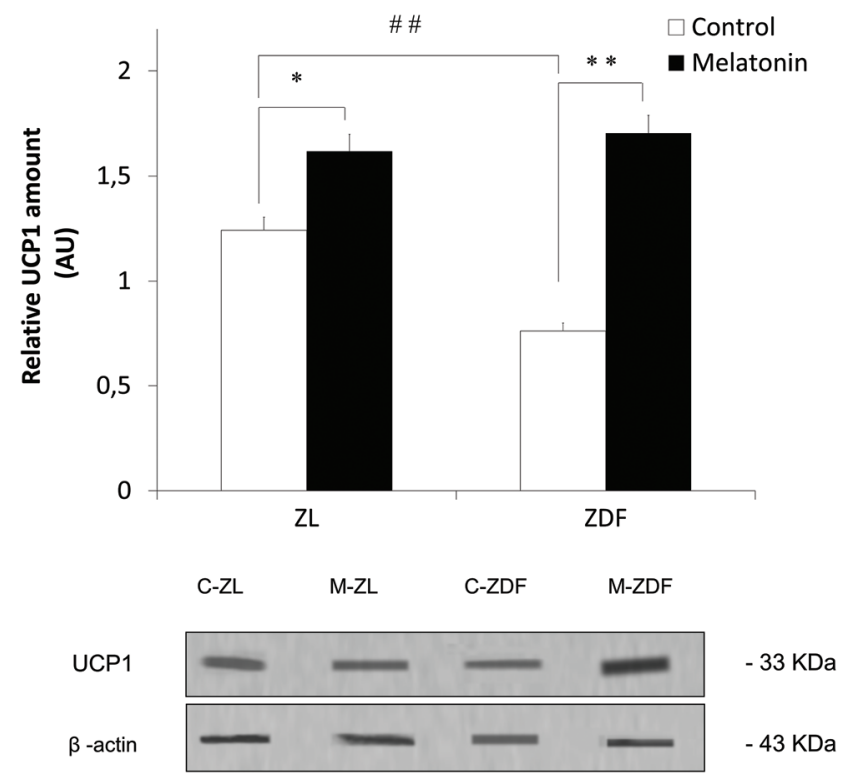

Fig. 3 Effects of in vivo melatonin supplementation on thermogenic protein UCP1 expression in MSCs of inguinal adipose tissue from Zücker rats. ZL, Zücker lean rats; ZDF, Zücker diabetic fatty rats; $C$, unsupplemented control; $M$, melatonin-supplemented. All values are expressed as mean \pm SEM of three independent experiments in duplicate. ${ }^{* *} P<$ $0.01 ;{ }^{\star} P<0.05 ; \# \#<0.01$. 
characterize the isolated cells using rat MSC specific markers CD-133 and stem cell antigen 1 (SCA-1), and CD-90, CD-73, CD-105, CD-34, CD-29, and CD-45 markers in both human and rat MSC. Cells were positive to CD-29, SCA-1, CD-105, CD-90 and CD-73, and negative to CD-45, CD-34 and CD-133 (Fig. 4A and B). Multipotency of isolated cells was tested by adipogenic, chondrogenic and osteogenic differentiation, and detected by oil red-O, toluidine, and alizarin red staining, respectively, after differentiation (Fig. 5A and B).

\subsection{Analysis of differentiated adipocytes}

After cell isolation from the inguinal WAT of ZDF rats and from human lipoaspirates, MSCs were subjected to adipogenesis assay to differentiate them into adipocytes (see Material and methods). Adipogenesis was successfully induced, and adipocytes were fully differentiated. Lipid droplet formation was examined by fluorescence microscopy (Fig. 6). AdipoRed staining enables the quantification of lipid droplets by measuring the absorbance at $520 \mathrm{~nm}$, demonstrating a higher

\section{A) ZDF rat}
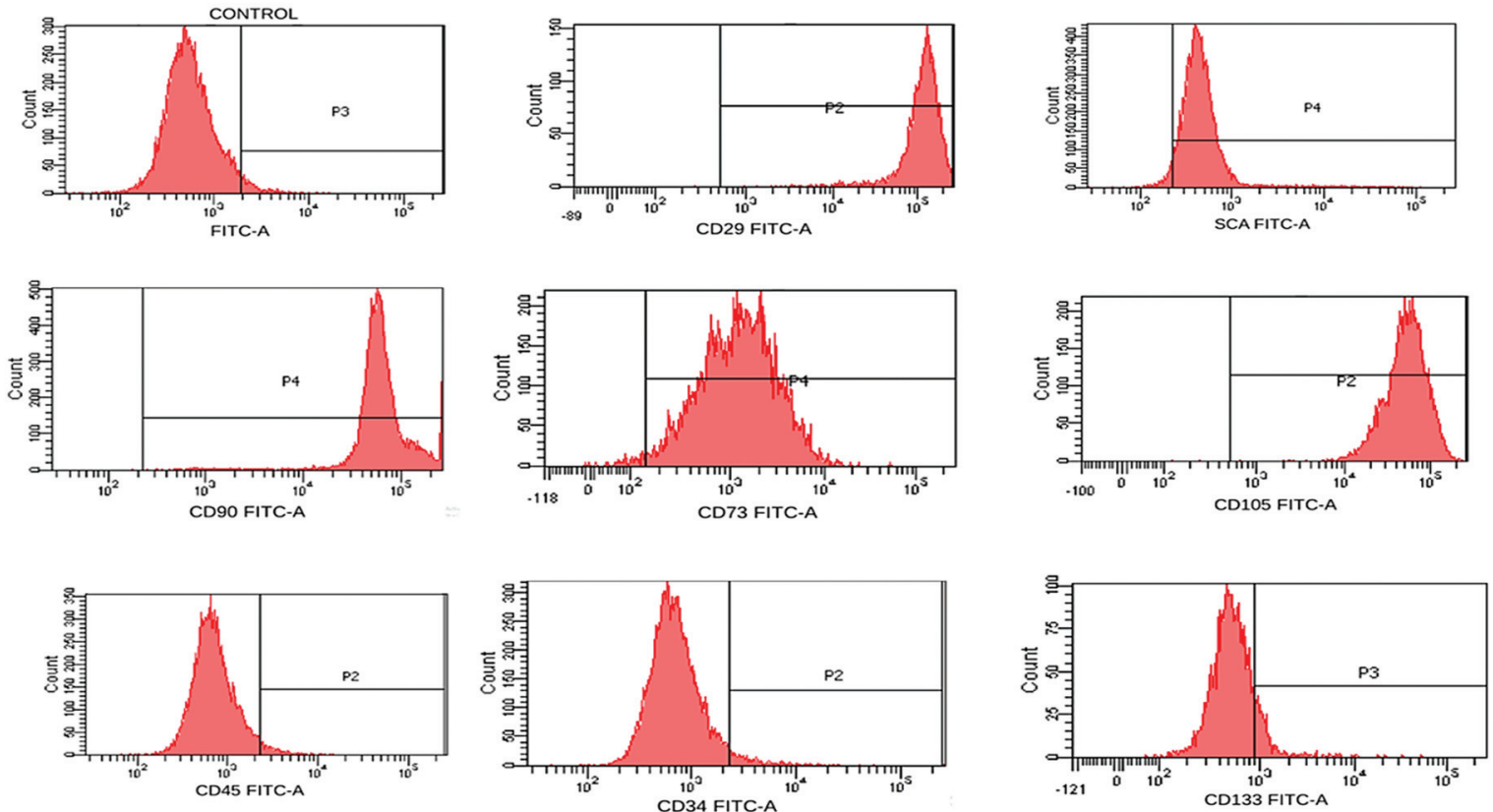

\section{B) Human}
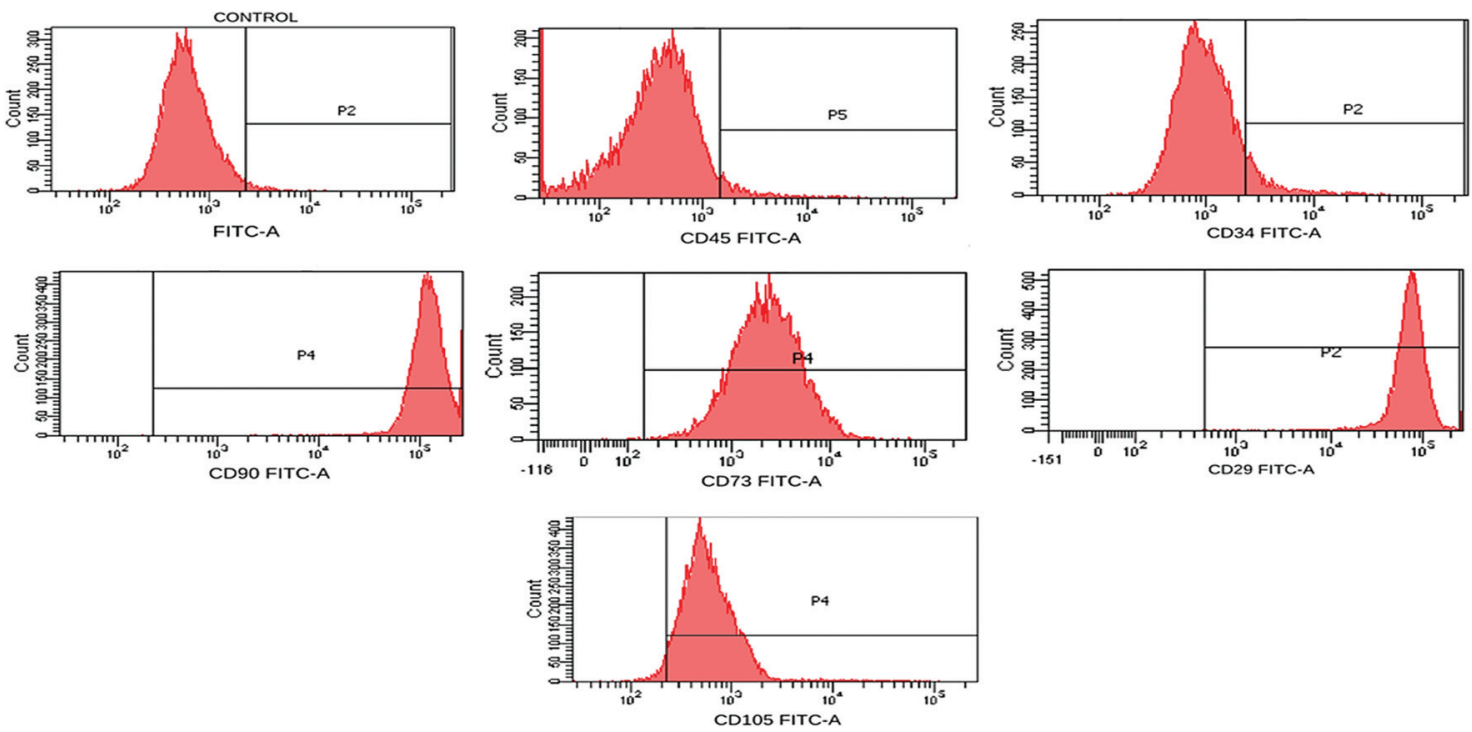

Fig. 4 Flow cytometry analysis of MSC isolated from (A) inguinal adipose tissue of Zücker rats and (B) human lipoaspirates. Samples without markers were used as a control. CD45, SCA-1, CD133, CD29 CD34, CD73, CD90 and CD105 were used as markers for MSC characterization. 


\section{A) ZDF rat}

1)
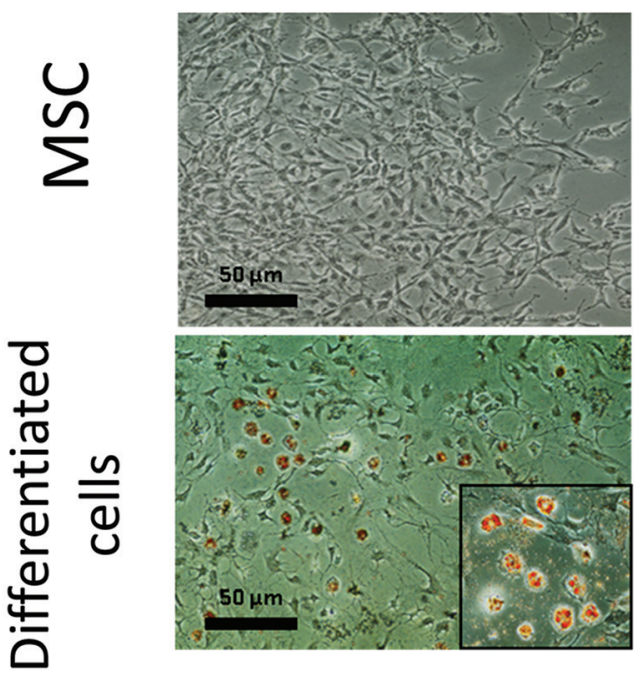

2)
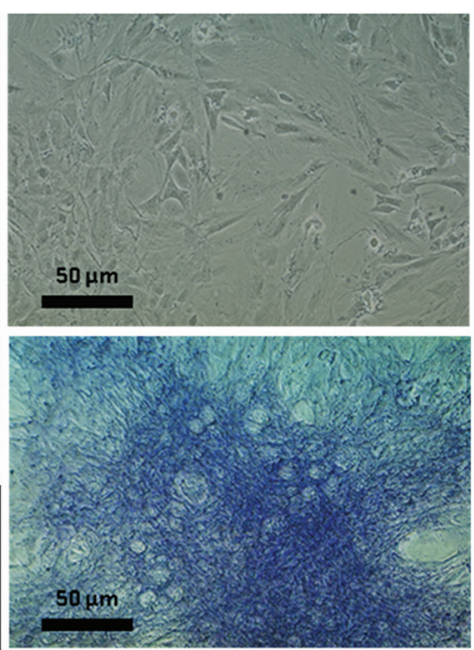

3)

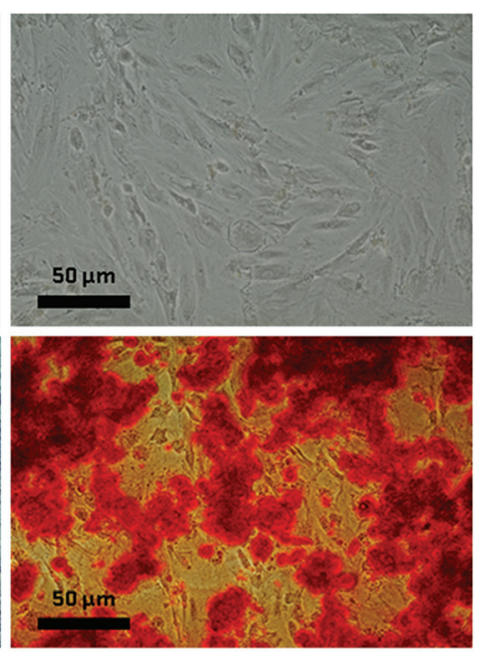

\section{B) Human}

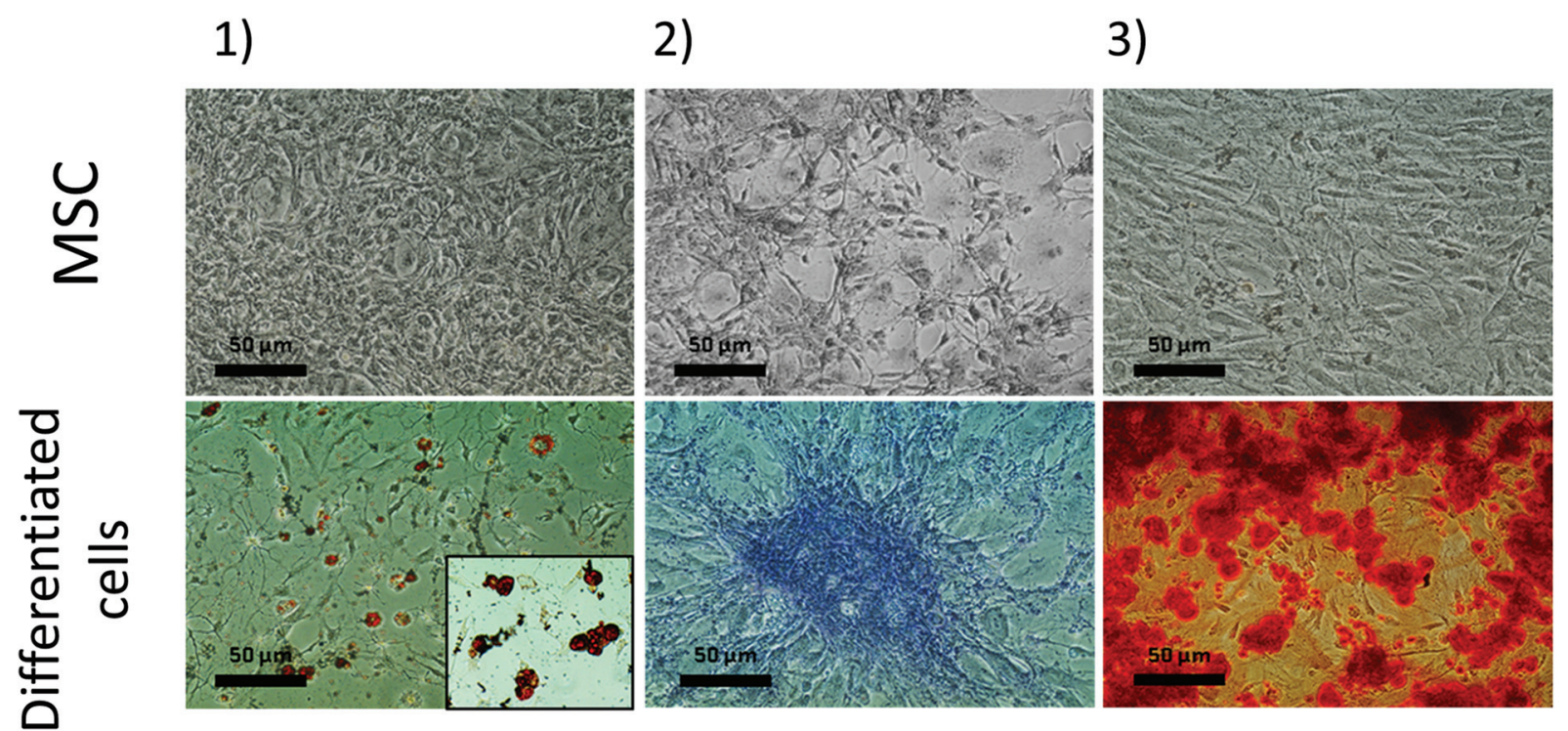

Fig. 5 In vitro characterization of cultured (A) Zücker rats and (B) human MSC. In both, in the upper panels, the images show MSC and in the lower panels, the differentiated cells from MSC after 21 days: (1) adipogenic, (2) chondrogenic and (3) osteogenic differentiation assay from optical microscopy. Magnification 40x. Scale bar $50 \mu \mathrm{m}$.

lipid content in differentiated adipocytes from both Zücker (MSC, $0.154 \pm 0.015$; differentiated adipocytes, $0.822 \pm 0.029 ; P$ $<0.01$; Fig. 6A) and human (MSC, $0.170 \pm 0.027$; differentiated adipocytes, $0.733 \pm 0.051 ; P<0.01$; Fig. $6 \mathrm{~B})$ isolated cells.

\subsection{In vitro melatonin treatment effects on UCP1, CITED1 and PGC1- $\alpha$ expression in ZDF rat MSCs}

The thermogenic protein UCP1 expression was measured by western blot in ZDF MSC, untreated adipocyte (adipocytes) and melatonin-treated adipocyte (Adipocytes + MLT) samples from both WMSC and bMSC iWAT from ZDF rat. No differences between WMSC and bMSC groups in UCP1 expression were found. Therefore, the WMSC and bMSC data were used interchangeably by recalculating the UCP1 expression of each group as the mean of the WMSC and bMSC expression. Melatonin in vitro treatment significantly induces UCP1 expression in differentiated adipocytes from ZDF MSCs (Adipocytes, $0.876 \pm 0.044$; Adipocytes + MLT, $1.063 \pm 0.018 ; P$ 


\section{A) ZDF rat}
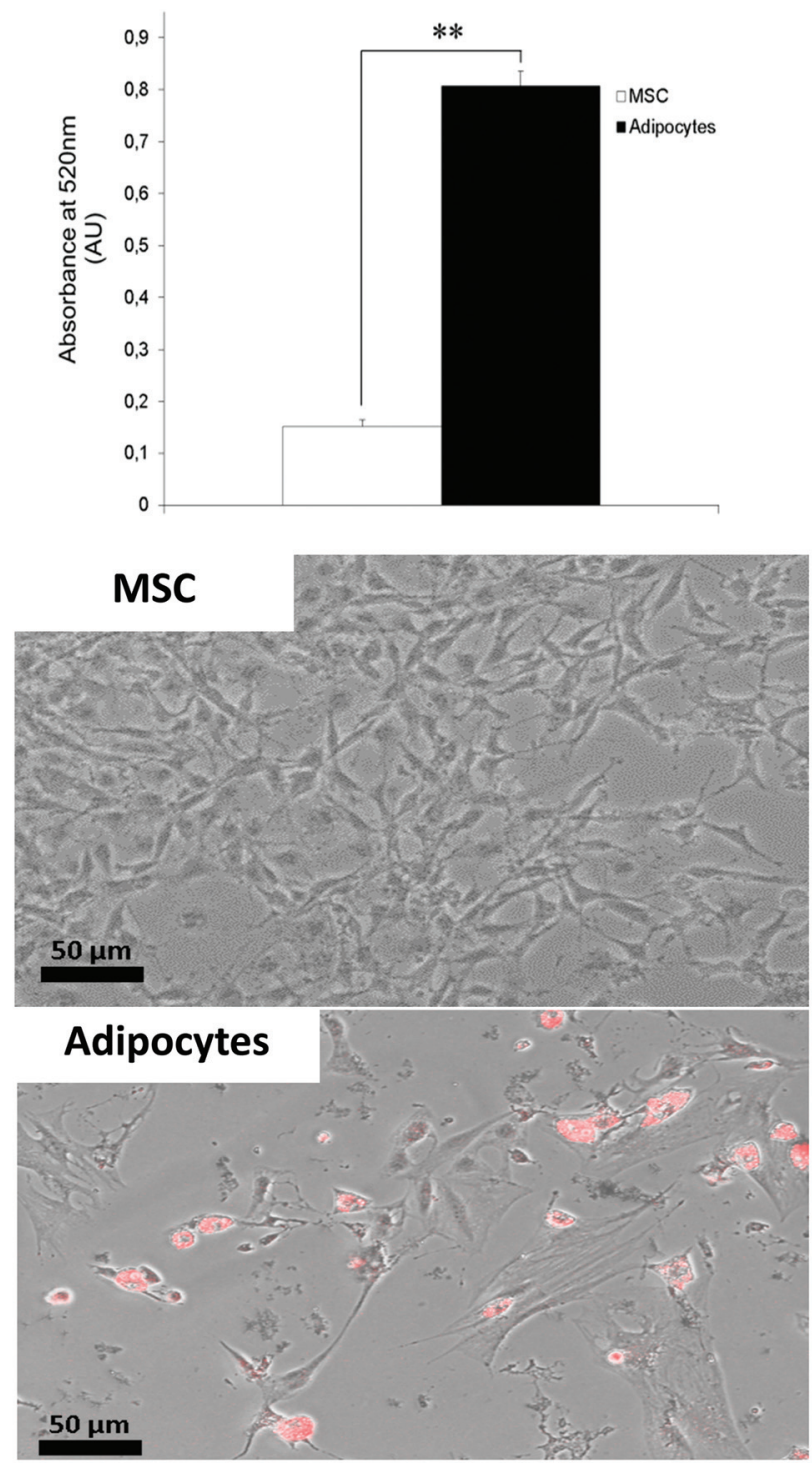

\section{B) Human}
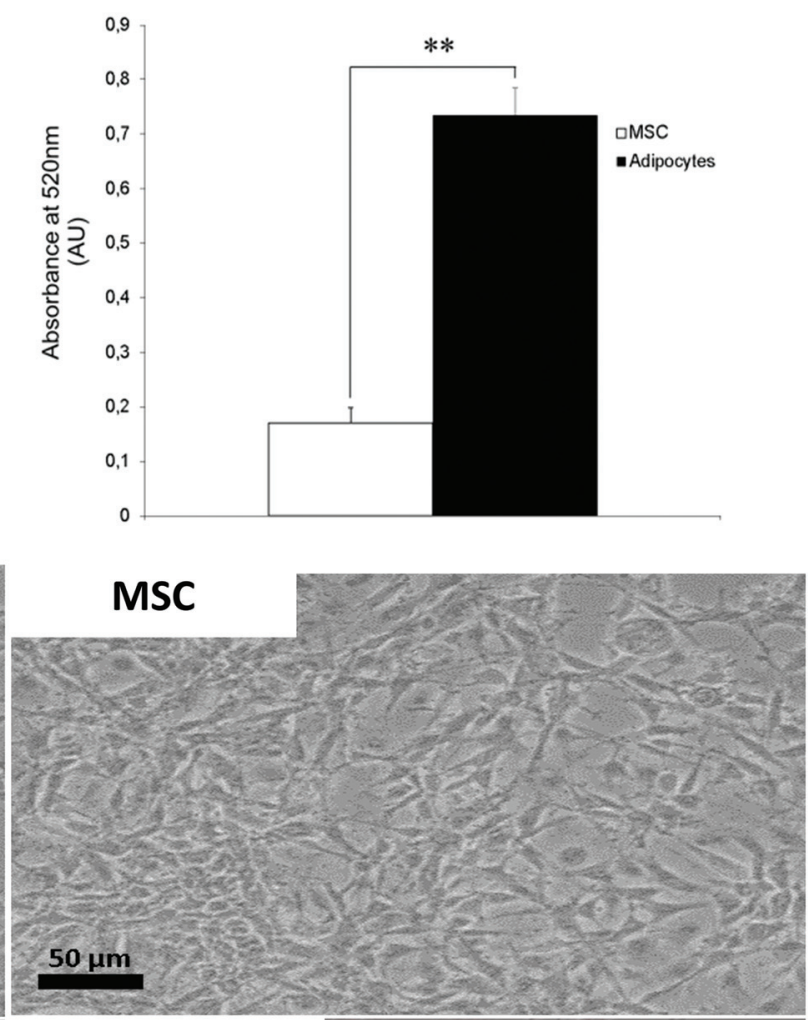

Adipocytes

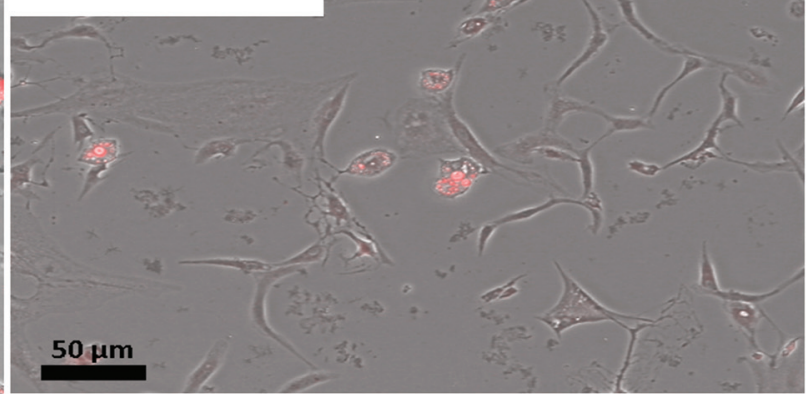

Fig. 6 Adipogenic differentiation of cultured MSC into adipocytes. Fluorescence microscopy images showed the lipid content in MSCs and differentiated adipocytes after in vitro melatonin treatment, measured by quantification of AdipoRed staining (absorbance at $520 \mathrm{~nm}$ ) from (A) Zücker rats and (B) humans. All values are expressed as mean \pm SEM of three independent experiments in duplicate. MSC, mesenchymal stem cells; Adipocytes, differentiated adipocytes after 21 days. Magnification $63 x$. Scale bar $50 \mu \mathrm{m}$. ${ }^{* *} P<0.01$.

$<0.05$; Fig. 7) resulting in higher brown-like adipogenesis. No differences in UCP1 expression between MSCs and untreated differentiated adipocytes were found.

PGC1- $\alpha$ and CITED1 expression in ZDF MSCs, untreated adipocytes and melatonin-treated adipocytes was also evaluated by the western blot technique. WMSC and bMSC inguinal adipose tissue from $\mathrm{ZDF}$ rats were isolated to study the extent to which melatonin achieves commitment of MSCs to the beige phenotype adipogenic lineage. MSCs from bMSC present both higher PGC1- $\alpha$ (bMSC, $0.534 \pm$ 0.026; WMSC, $0.476 \pm$
0.015; $P<0.05$; Fig. 8A) and CITED1 (bMSC, $0.323 \pm 0.009$; WMSC, $0.236 \pm 0.012 ; P<0.05$; Fig. 8B) expression levels than WMSC, suggesting a greater MSCs commitment to thermogenic beige adipocytes. After adipogenesis, no significant differences in CITED1 and PGC1- $\alpha$ expression between adipocytes differentiated from bMSC and WMSC were found regardless of the adipogenic differentiation assay. However, comparing groups, the melatonin-treated adipogenesis assay induces a significantly greater PGC1- $\alpha$ expression in differentiated ZDF adipocytes from both bMSCs (Adipocytes + MLT, $0.731 \pm 0.043$; 


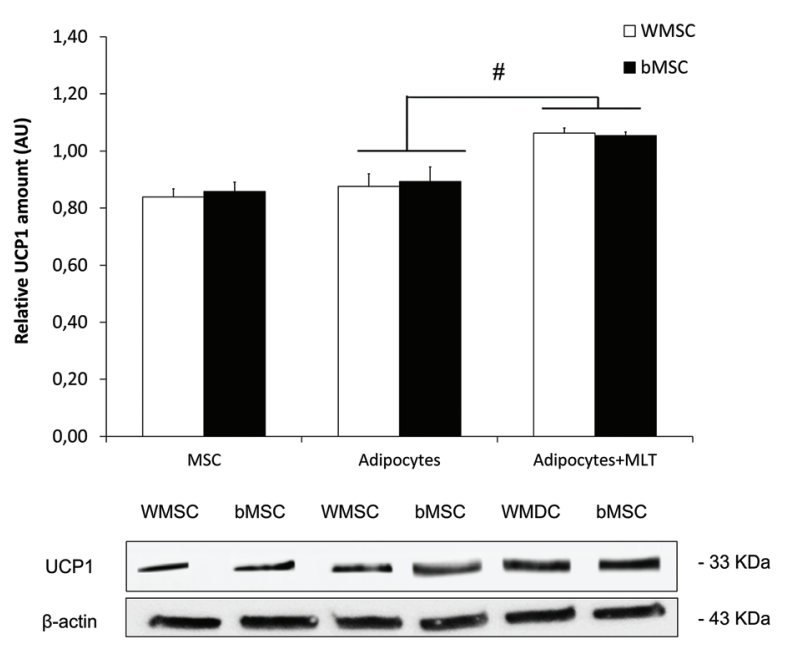

Fig. 7 Effects of in vitro melatonin treatment on thermogenic protein UCP1 in differentiated adipocytes from WMSCs and bMSC inguinal adipose tissue from ZDF rats. MSC, mesenchymal stem cells; Adipocytes, differentiated adipocytes after 21 days, Adipocytes + MLT, differentiated adipocytes after 21 days incubated with melatonin. All values are expressed as mean \pm SEM of three independent experiments in duplicate. $\# P<0.05$.

Adipocytes, $0.503 \pm 0.034 ; P<0.05$ ) and WMSCs (Adipocytes + MLT, $0.724 \pm 0.066$; Adipocytes, $0.558 \pm 0.054 ; P<0.05$ ), suggesting that melatonin increases the commitment of MSCs to differentiated brown-like adipocytes (Fig. 8A). Furthermore, the adipogenesis assay increases CITED1 expression in ZDF differentiated adipocytes compared to MSCs regardless of their origin, with significantly higher CITED1 expression in melatonin-treated adipocytes than in treated ones (MSC, $0.280 \pm$ 0.052; Adipocytes, $0.528 \pm 0.054$; Adipocytes + MLT, $0.679 \pm$ 0.038; on average; $P<0.01$; Fig. 8B).

\subsection{In vitro melatonin treatment effects on UCP1, CITED1 and PGC1- $\alpha$ expression in human MSCs}

Western blot techniques were accomplished to measure UCP1, PGC1- $\alpha$ and CITED1 expression levels in lipoaspirate-derived human MSCs (hMSC), untreated hMSC-differentiated adipocytes (Adipocytes) and melatonin-treated hMSC-differentiated adipocytes (Adipocytes + MLT). In vitro melatonin treatment induces the expression of both thermogenic markers UCP1 (Adipocytes, $1.135 \pm 0.038$; Adipocytes + MLT, $1.284 \pm 0.030 ; P$ $<0.05$; Fig. 9A) and PGC1- $\alpha$ (Adipocytes, $3.130 \pm 0.038$; Adipocytes + MLT, $3.483 \pm 0.130 ; P<0.05$; Fig. 9B) in hMSCs from healthy donors' lipoaspirates with significant expression differences between untreated and melatonin-treated differentiated adipocytes.

Moreover, the expression of the beige adipocyte marker CITED1 experiences a highly significant increase with melatonin treatment (Adipocytes, $0.645 \pm 0.089$; Adipocytes + MLT, $0.946 \pm 0.078 ; P<0.01$; Fig. 9C). No significant differences between hMSCs and untreated adipocytes were found in any expression of the measured thermogenic proteins.
A)
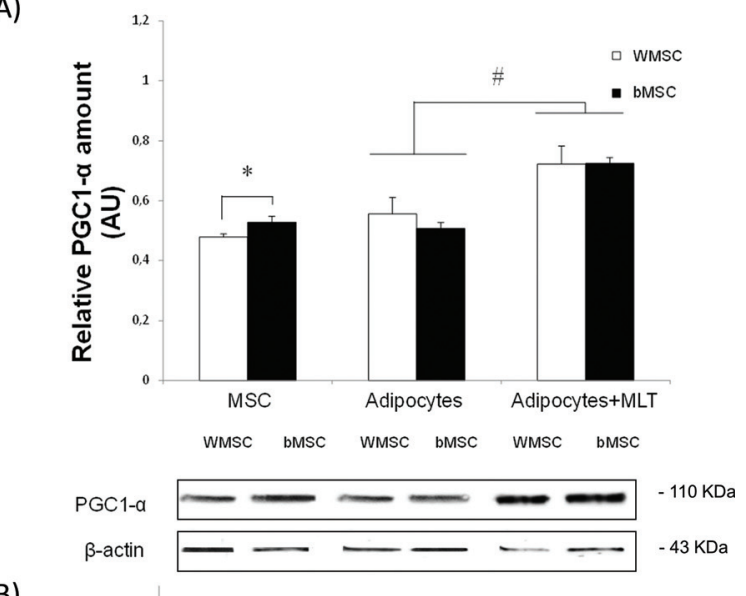

B)

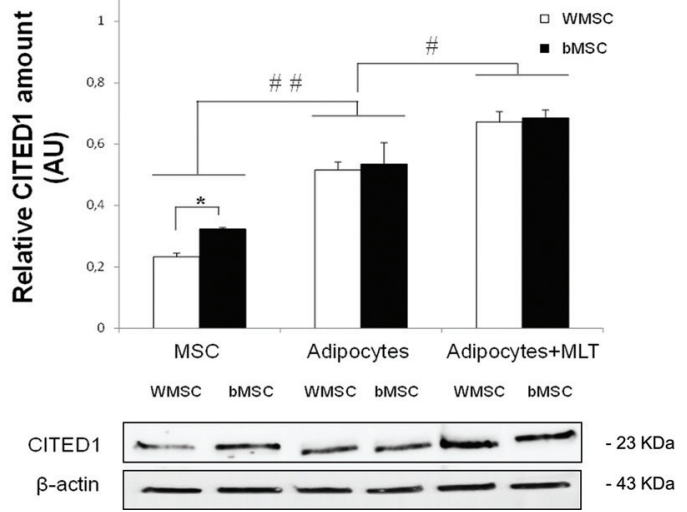

Fig. 8 Effects of in vitro melatonin treatment on brown-like cell marker (A) PGC1- $\alpha$ and (B) CITED1 expression in differentiated adipocytes from WMSCs and bMSC inguinal adipose tissue from ZDF rats. MSC, mesenchymal stem cells; Adipocytes, differentiated adipocytes after 21 days, Adipocytes + MLT, differentiated adipocytes after 21 days incubated with melatonin. All values are expressed as mean \pm SEM of three independent experiments in duplicate. ${ }^{*} P<0.01$; ${ }^{*} P<0.05$.

\section{Discussion}

We previously reported that melatonin induces inguinal WAT browning in obese and diabetic Zücker rats, validating these results through the increased expression of UCP1. These results demonstrated that chronic oral melatonin drives WAT to brown multilocular fat function in ZDF rats. ${ }^{25}$ In this study, our group also demonstrated through light microscopy morphological studies that unsupplemented ZDF rats present a smaller but larger number of adipocytes with a single fat drop and peripheral nucleus (white adipocytes) in the inguinal WAT of ZDF rats compared to the thin ones. ${ }^{25}$ All these data are consistent with the lower fluorescence signal in unsupplemented ZDF rats and the partially recovered one in melatonin-supplemented ZDF rats by the appearance of multilocular cells (beiging) observed in this study. The increased expression of UCP1 is related to thermogenically active brown and beige adipose tissues. ${ }^{47}$ However, beige/brite cells have a different gene expression pattern than white or brown fat cells. ${ }^{6}$ Indeed, CITED1 is known to be selectively expressed in beige cells and 
A)

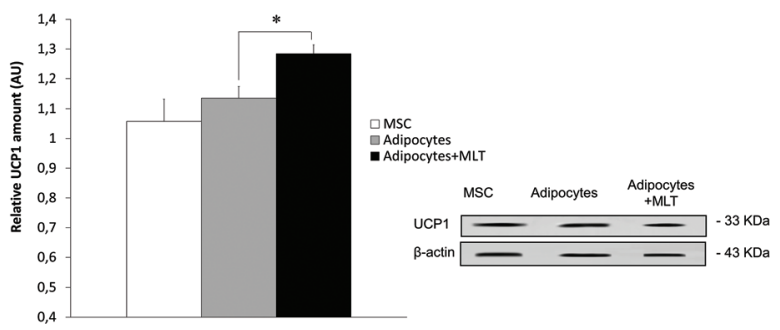

B)

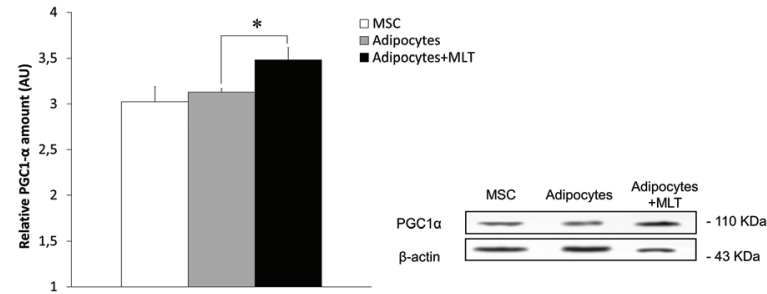

C)

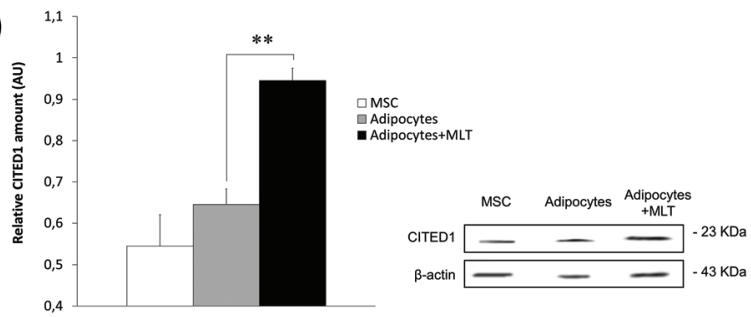

Fig. 9 Effects of in vitro melatonin treatment on thermogenic protein (A) UCP1, (B) PGC1- $\alpha$ and (C) brown-like cell marker CITED1 expression in differentiated adipocytes from hMSCs isolated from lipoaspirates' adipose tissue. MSC, human mesenchymal stem cells; Adipocytes, differentiated adipocytes after 21 days; Adipocytes + MLT, differentiated adipocytes after 21 days incubated with melatonin. All values are expressed as mean \pm SEM of three independent experiments in duplicate. ${ }^{*} P<0.01 ; * P<0.05$.

to act as a transcriptional coactivator for estrogen receptors that were originally identified in a murine melanoma cell line. ${ }^{10,11}$ In contrast, ASC- 1 is found to be a large surface marker for WAT due to its high expression in this tissue, with negligible or no expression in BAT. ${ }^{7,8}$

Herein, we report for the first time that oral melatonin administration not only induces UCP1 and CITED1 positive beige adipocyte biogenesis in inguinal WAT from obese Zücker rats, but also decreases the ASC-1 expression in inguinal fat from both obese and lean Zücker rats, which confirm a reduced white adipocyte amount in inguinal WAT depots, in line with I. Murano et al. observations about the decline in the number of white adipose cells. ${ }^{48}$ These results could explain the origin of melatonin-induced beige adipocytes by the partial transdifferentiation of white adipocytes to beige ones. This direct conversion process has been also demonstrated after cold acclimatization and concluded to be mainly mediated by the $\beta-3$ adrenergic receptor. ${ }^{31}$ However, more studies are needed to understand this biological process. Moreover, western blot analysis revealed that ASC-1 expression is higher in obese rats than in lean ones, indicating increased inguinal WAT mass, typically observed in obese rodents. ${ }^{49}$ Partial transdifferentiation shown alone cannot explain the elevated beiging process observed in the inguinal WAT from ZDF rats after melatonin supplementation, suggesting a MSC de novo differentiation into beige adipocytes.

MSCs, which are multipotent stem cells, have the ability to turn into mature adipocytes in the final phase of differentiation under certain types of stimuli. ${ }^{50}$ Therefore, as partial transdifferentiation was suggested in rats by the immunofluorescence assay, de novo differentiation studies of MSCs to mature adipocytes were performed to assess both hypotheses about the origin of melatonin-induced beige adipocytes in inguinal WAT of obese rats and in humans.

The isolation and characterization of inguinal fat and liposuction cells were performed by flow cytometry using, as proposed by the International Society for Cell Therapy (ISCT), positive MSC-specific surface markers such as CD-90, CD-73 and CD-105, and negatives like CD-34 and CD-45. In addition, other commonly measured surface markers were used in MSC characterization such as CD-29, a positive marker for both human and rat MSCs, SCA-1, a positive marker only for murine MSCs, and CD-133, a marker negative for MSC and only positive for hematopoietic stem cells. ${ }^{51}$ After characterization and the adipogenesis process, cells underwent in an in vitro melatonin treatment that mimicked the light-dark life cycle of circulating melatonin. ${ }^{52,53}$

The high expression of UCP1 has been associated with thermogenic adipose tissue, as well as with brown adipocytes. ${ }^{6,37,41,47}$ The specific differentiation of MSCs to beige/brite adipocytes with rosiglitazone increases the expression of thermogenic genes such as UCP1 in rodents ${ }^{54}$ and humans. ${ }^{55,56}$ The cold-induced browning of WAT deposits in rodents and humans is assessed by measuring the expression of UCP1. ${ }^{57,58}$ Cold exposure also induces MSC browning by increasing UCP1 expression in adipocytes differentiated from MSCs. ${ }^{59}$ In this study, we report that in vitro melatonin treatment increases UCP1 expression in MSC-differentiated adipocytes, suggesting increased brown-type adipogenesis in human and rat-treated MSCs. Another study that compared the white and brown human adipogenesis of MSCs and umbilical cord stem cells showed no differences in the expression of UCP1 between MSCs and differentiated white adipocytes, ${ }^{60}$ agreeing with the data observed in MSCs and differentiated adipocytes from inguinal WAT of ZDF rats and human lipoaspirates. Various studies in humans ${ }^{61}$ and rodents $^{59}$ revealed that MSCs and preadipocytes involved in adipogenesis showed the increased expression of thermogenic genes such as UCP1, indicating their thermogenic potential. These data are consistent with those obtained after in vivo melatonin supplementation reported in this research, in which MSC UCP1 expression increases in both lean and obese supplemented Zücker rats, showing a greater thermogenic potential for beige adipogenesis. Furthermore, we observed that the expression of UCP1 in unsupplemented obese rats was lower than that in unsupplemented lean rats, suggesting a decrease in the compromise in MSCs derived from ZDF rats and a lower 
thermogenic activity of future differentiated adipocytes. In humans, subcutaneous WAT-derived MSCs from obese patients also exhibit less expression of PGC1- $\alpha$, CITED1, and UCP1 than lean MSCs, with decreased changes in thermogenic gene expression between pre- and post-differentiation. ${ }^{62}$ In this study, we also report for the first time that melatonin induces the expression of thermogenic proteins UCP1, CITED1 and PGC1- $\alpha$ in hMSC-derived adipocytes, revealing the role of melatonin in human de novo beige adipogenesis. Although some studies demonstrate the key role that the Wnt signaling pathway plays in the melatonin-induced differentiation of MSCs through the modulation of transcriptional activation of peroxisome proliferator-activated receptor $\gamma$ (PPAR $\gamma$ ), ${ }^{63}$ SIRT1 being the key nutrient and energy sensor underlying Wnt/ $\beta$-catenin pathway activation. A recent study also showed that PDGFR $\alpha$ positive progenitors are crucial for de novo brown adipogenesis in interscapular adipose tissue under cold exposure, being also a good candidate target for adipogenesis regulation in the development of adipose tissue. ${ }^{44}$ Further studies are needed to better understand the mechanism by which melatonin could have a decisive effect on MSC involvement with thermogenically active beige adipocytes in vivo increasing MSC commitment.

To evaluate the beige biogenesis potential of melatonin in cultured MSCs, we performed the characterization of differentiated adipocytes by measuring CITED1 as a specific beige cell marker. ${ }^{9}$ Moreover, we determined the PGC1- $\alpha$ expression commonly associated with adaptive thermogenesis and mitochondrial biogenesis in rodents ${ }^{64,65}$ and humans, ${ }^{66}$ besides being highly expressed in brown-like adipocytes. CITED1 and PGC1- $\alpha$ expression was higher in melatonin-treated differentiated adipocytes compared to untreated ones and undifferentiated MSCs in both studied species. This reaffirms the hypothesis that melatonin increases specific beige adipogenesis. Other studies demonstrated that cold ${ }^{59}$ and adrenergic stimulation by sirtuin 1 (SIRT1) ${ }^{67,68}$ or bone morphogenetic protein 7 (BMP7) ${ }^{69}$ also promote the thermogenic gene program, enhancing UCP1, PGC1- $\alpha$ and PR-domain containing 16 (PRDM16) expression, and high expression of beige adipocyte markers like CITED1, purinergic receptor P2X 5 (P2RX5) and CD137 in differentiated adipocytes. Recent studies in MSC differentiation to BAT in humans revealed that the increased expression of PGC1- $\alpha$ in MSCs is related to higher mitochondrial mass and activity, with higher UCP1 expression (mitochondrial biogenesis), typically observed in beige and brown adipocytes. $^{70}$ They also found by microarray analysis that PGC1- $\alpha$ expressing MSCs has a shorter average linkage distance to mature brown adipocytes, showing a greater commitment to brown-like adipogenesis.

CITED1 was highly expressed in adipocytes differentiated from untreated inguinal MSCs, and the data are consistent with many studies in mice where the authors demonstrated that subcutaneous and especially inguinal adipose tissue are more prone to become thermogenic beige adipose tissue. ${ }^{71,72}$ We also observed that the expression of CITED1 and PGC1- $\alpha$ was significantly higher in MSCs derived from beige deposits of the inguinal fat pad than in white ones, which suggests a greater commitment of MSCs with the differentiation of thermogenic beige adipocytes in the bMSCs than WMSCs. This could be explained by the epigenomic memory found in beige adipocytes, ${ }^{46}$ which could be present in BAT and explain similar data obtained in mice ${ }^{73}$ and human studies ${ }^{60,74,75}$ in which derived MSCs from BAT were found to express higher levels of thermogenic proteins. A long-term cold exposure study in mice revealed that de novo beige biogenesis was favored from adipogenic precursor cells, ${ }^{76}$ suggesting that the beige biogenesis mechanism, either by darkening of pre-existing mature adipocytes or de novo differentiation, also depends on the frequency and duration of stimuli such as cold. ${ }^{77}$ Therefore, these are two key variables in the melatonin regulation of MSC adipogenesis as a promising therapeutic target for obesity control. In addition, other effects of melatonin were recently demonstrated on mesenchymal stem cells derived from the umbilical cord blood of obese rodents that reduce cholesterol accumulation and prevent apoptosis of MSCs, supporting the therapeutic role of melatonin against obesity. ${ }^{78} \mathrm{~A}$ recent meta-analysis of the effects of melatonin in human obesity studies showed that, despite the evidence found in the energy balance of rodents and humans, ${ }^{79,80}$ the real impact of melatonin on body weight loss remains unclear due to the inconsistent melatonin treatment schedule regarding duration and low dose (0.01-0.1 mg kg $\left.\mathrm{kg}^{-1} \mathrm{day}^{-1}\right)$ in all studies. Overall, these data provide evidence that, under melatonin treatment, the de novo differentiation of beige cells in ZDF rats and humans probably occurs in conjunction.

\section{Conclusions}

In conclusion, with these results, it is demonstrated that the administration of melatonin to obese and diabetic ZDF rats induces beige biogenesis by the partial transdifferentiation of white to beige adipocytes, reducing the amount of white adipose cells and the differentiation of MSCs in the inguinal adipose tissue. In addition, melatonin plays a key role in the beige adipogenesis of human MSCs, promoting MSC engagement with the brown-type thermogenic adipocyte lineage and enhancing the expression of thermogenic markers. Therefore, as a thermogenic inducer of browning, melatonin could be a safe and effective strategy to combat obesity and metabolic diseases. More studies on the nuclear-mitochondrial connection are needed to better understand the thermogenic pathways involved, with melatonin receptors and mitochondrial DNA being fundamental study targets to identify mitochondrialnucleus communication in melatonin treatment for human obesity and diabetes.

\section{Ethical statement}

The study was conducted according to the guidelines of the Declaration of Helsinki and approved by the Ethical 
Committee of the University of Granada (Granada, Spain) (4 09-2016-CEEA and 02/022010). Informed consent was obtained from all subjects involved in the study.

\section{Author contributions}

AA conception and design, financial support, manuscript writing, final approval of manuscript. DS, MNA and MC collection and assembly of data, data analysis and interpretation, manuscript writing. GFV, MJOL, AMH and AMC manuscript writing. All authors have read and agreed to the published version of the manuscript.

\section{Conflicts of interest}

The authors declare that there are no conflicts of interest.

\section{Acknowledgements}

This research was partially supported by grant SAF2016-79794$\mathrm{R}$ from the Ministerio de Ciencia e Innovación (Spain), European Regional Development Fund (ERDF), University of Granada and FEDER Funds grant number B-CTS-102-UGR20. The authors thank Antonio Tirado for their technical assistance.

\section{References}

1 S. B. Racette, S. S. Deusinger and R. H. Deusinger, Obesity: Overview of Prevalence, Etiology, and Treatment, Phys. Ther., 2003, 83, 276-288.

2 A. H. de Mello, A. B. Costa, J. D. G. Engel and G. T. Rezin, Mitochondrial dysfunction in obesity, Life Sci., 2018, 192, 26-32.

3 S. Hummasti and G. S. Hotamisligil, Endoplasmic reticulum stress and inflammation in obesity and diabetes, Circ. Res., 2010, 107, 579-591.

4 World Health Organization, Fact Sheet Obesity and overweight, http:/www.who.int/mediacentre/factsheets/fs311/ en/.

5 E. S. Bachman, H. Dhillon, C. Y. Zhang, S. Cinti, A. C. Bianco, B. K. Kobilka and B. B. Lowell, $\beta$ AR signaling required for diet-induced thermogenesis and obesity resistance, Science, 2002, 297, 843-845.

6 A. Park, Distinction of white, beige and brown adipocytes derived from mesenchymal stem cells, World J. Stem Cells, 2014, 6, 33-42.

7 A. Grigoraş, C. Amalinei, R. A. Balan, S. E. Giuşcă, E. R. Avădănei, L. Lozneanu and I. D. Căruntu, Adipocytes spectrum-From homeostasia to obesity and its associated pathology, Ann. Anat., 2018, 219, 102-120.

8 S. Ussar, K. Y. Lee, S. N. Dankel, J. Boucher, M. F. Haering, A. Kleinridders, T. Thomou, R. Xue, Y. Macotela,
A. M. Cypess, Y. H. Tseng, G. Mellgren and C. R. Kahn, ASC-1, PAT2, and P2RX5 are cell surface markers for white, beige, and brown adipocytes, Sci. Transl. Med., 2014, 6, 247 ra103.

9 L. Z. Sharp, K. Shinoda, H. Ohno, D. W. Scheel, E. Tomoda, L. Ruiz, H. Hu, L. Wang, Z. Pavlova, V. Gilsanz and S. Kajimura, Human BAT Possesses Molecular Signatures That Resemble Beige/Brite Cells, PLoS One, 2012, 7, e49452.

10 T. Shioda, M. H. Fenner and K. J. Isselbacher, msg1, A novel melanocyte-specific gene, encodes a nuclear protein and is associated with pigmentation, Proc. Natl. Acad. Sci. U. S. A., 1996, 93, 12298-12303.

11 T. Yahata, W. Shao, H. Endoh, J. Hur, K. R. Coser, H. Sun, Y. Ueda, S. Kato, K. J. Isselbacher, M. Brown and T. Shioda, Selective coactivation of estrogen-dependent transcription by CITED1 CBP/p300-binding protein, Genes Dev., 2001, 15, 2598-2612.

12 A. M. Cypess, A. P. White, C. Vernochet, T. J. Schulz, R. Xue, C. A. Sass, T. L. Huang, C. Roberts-Toler, L. S. Weiner, C. Sze, A. T. Chacko, L. N. Deschamps, L. M. Herder, N. Truchan, A. L. Glasgow, A. R. Holman, A. Gavrila, P. O. Hasselgren, M. A. Mori, M. Molla and Y. H. Tseng, Anatomical localization, gene expression profiling and functional characterization of adult human neck brown fat, Nat. Med., 2013, 19, 635-639.

13 R. J. Wurtman, J. Axelrod and L. S. Phillips, Melatonin synthesis in the pineal gland: Control by light, Science, 1963, 142, 1071-1073.

14 W. B. Quay, Circadian and Estrous Rhythms in Pineal Melatonin and 5-Hydroxy Indole-3-Acetic Acid, Proc. Soc. Exp. Biol. Med., 1964, 115, 710-713.

15 J. Stefulj, M. Hörtner, M. Ghosh, K. Schauenstein, I. Rinner, A. Wölfler, J. Semmler and P. M. Liebmann, Gene expression of the key enzymes of melatonin synthesis in extrapineal tissues of the rat, J. Pineal Res., 2001, 30, 243-247.

16 R. J. Reiter, S. D. Paredes, L. C. Manchester and D.-X. Tan, Reducing oxidative/nitrosative stress: a newly-discovered genre for melatonin, Crit. Rev. Biochem. Mol. Biol., 2009, 44, 175-200.

17 G. Cheng, T. Ma, Z. Deng, G. Gutiérrez-Gamboa, Q. Ge, P. Xu, Q. Zhang, J. Zhang, J. Meng, R. J. Reiter, Y. Fang and X. Sun, Plant-derived melatonin from food: A gift of nature, Food Funct., 2021, 12, 2829-2849.

18 M. Navarro-Alarcón, F. J. Ruiz-Ojeda, R. M. Blanca-Herrera, M. M. A-Serrano, D. Acuña-Castroviejo, G. FernándezVázquez and A. Agil, Melatonin and metabolic regulation: A review, Food Funct., 2014, 5, 2806-2832.

19 T. Wolden-Hanson, D. R. Mitton, R. L. McCants, S. M. Yellon, C. W. Wilkinson, A. M. Matsumoto and D. D. Rasmussen, Daily melatonin administration to middle-aged male rats suppresses body weight, intraabdominal adiposity, and plasma leptin and insulin independent of food intake and total body fat, Endocrinology, 2000, 141, 487-497. 
20 B. Prunet-Marcassus, M. Desbazeille, A. Bros, K. Louche, P. Delagrange, P. Renard, L. Casteilla and L. Pénicaud, Melatonin Reduces Body Weight Gain in Sprague Dawley Rats with Diet-Induced Obesity, Endocrinology, 2003, 144, 5347-5352.

21 M. A. Raskind, B. L. Burke, N. J. Crites, A. M. Tapp and D. D. Rasmussen, Olanzapine-induced weight gain and increased visceral adiposity is blocked by melatonin replacement therapy in rats, Neuropsychopharmacology, 2007, 32, 284-288.

22 A. Agil, M. Navarro-Alarcõn, R. Ruiz, S. Abuhamadah, M. Y. El-Mir and G. F. Vázquez, Beneficial effects of melatonin on obesity and lipid profile in young Zucker diabetic fatty rats, J. Pineal Res., 2011, 50, 207-212.

23 M. P. Terrón, J. Delgado-Adámez, J. A. Pariente, C. Barriga, S. D. Paredes and A. B. Rodríguez, Melatonin reduces body weight gain and increases nocturnal activity in male Wistar rats, Physiol. Behav., 2013, 118, 8-13.

24 Y. Isobe, T. Torri, E. Konishi and J. Fujioi, Effects of melatonin injection on running-wheel activity and body temperature differ by the time of day, Pharmacol., Biochem. Behav., 2002, 73, 805-811.

25 A. Jiménez-Aranda, G. Fernández-Vázquez, D. Campos, M. Tassi, L. Velasco-Perez, D. X. Tan, R. J. Reiter and A. Agil, Melatonin induces browning of inguinal white adipose tissue in Zucker diabetic fatty rats, J. Pineal Res., 2013, 55, 416-423.

26 A. Agil, I. Rosado, R. Ruiz, A. Figueroa, N. Zen and G. Fernández-Vázquez, Melatonin improves glucose homeostasis in young Zucker diabetic fatty rats, J. Pineal Res., 2012, 52, 203-210.

27 W. Zhu, K. K. Y. Cheng, P. M. Vanhoutte, K. S. L. Lam and A. Xu, Vascular effects of adiponectin: molecular mechanisms and potential therapeutic intervention., Clin. Sci., 2008, 114, 361-374.

28 S. Roman, A. Agil, M. Peran, E. Alvaro-Galue, F. J. RuizOjeda, G. Fernández-Vázquez and J. A. Marchal, Transl. Res., 2015, 165, 464-479.

29 D. X. Tan, L. C. Manchester, L. Fuentes-Broto, S. D. Paredes and R. J. Reiter, Significance and application of melatonin in the regulation of brown adipose tissue metabolism: Relation to human obesity, Obes. Rev., 2011, 12, 167-188.

30 P. Seale, H. M. Conroe, J. Estall, S. Kajimura, A. Frontini, J. Ishibashi, P. Cohen, S. Cinti and B. M. Spiegelman, Prdm16 determines the thermogenic program of subcutaneous white adipose tissue in mice, J. Clin. Invest., 2011, 121, 96-105.

31 G. Barbatelli, I. Murano, L. Madsen, Q. Hao, M. Jimenez, K. Kristiansen, J. P. Giacobino, R. de Matteis and S. Cinti, The emergence of cold-induced brown adipocytes in mouse white fat depots is determined predominantly by white to brown adipocyte transdifferentiation, Am. J. Physiol.: Endocrinol. Metab, 2010, 298, e1244-e1253.

32 P. Boström, J. Wu, M. P. Jedrychowski, A. Korde, L. Ye, J. C. Lo, K. A. Rasbach, E. A. Boström, J. H. Choi, J. Z. Long, S. Kajimura, M. C. Zingaretti, B. F. Vind, H. Tu, S. Cinti, K. Højlund, S. P. Gygi and B. M. Spiegelman, A PGC1- $\alpha$-dependent myokine that drives brown-fat-like development of white fat and thermogenesis, Nature, 2012, 481, 463-468.

33 B. Cousin, S. Cinti, M. Morroni, S. Raimbault, D. Ricquier, L. Penicaud and L. Casteilla, Occurrence of brown adipocytes in rat white adipose tissue: Molecular and morphological characterization, J. Cell Sci., 1992, 103, 931-942.

34 X. Ma, P. Lee, D. J. Chisholm and D. E. James, Control of adipocyte differentiation in different fat depots; Implications for pathophysiology or therapy, Front. Endocrinol., 2015, 6, 1.

35 N. Haider and L. Larose, Harnessing adipogenesis to prevent obesity, Adipocyte, 2019, 8, 98-104.

36 M. Harms and P. Seale, Brown and beige fat: Development, function and therapeutic potential, Nat. Med., 2013, 19, 1252-1263.

37 A. Vargas-Castillo, R. Fuentes-Romero, L. A. RodriguezLopez, N. Torres and A. R. Tovar, Understanding the Biology of Thermogenic Fat: Is Browning A New Approach to the Treatment of Obesity?, Arch. Med. Res., 2017, 48, 401-413.

38 Q. A. Wang, C. Tao, R. K. Gupta and P. E. Scherer, Tracking adipogenesis during white adipose tissue development, expansion and regeneration, Nat. Med., 2013, 19, 13381344.

39 C. Hepler and R. K. Gupta, The expanding problem of adipose depot remodeling and postnatal adipocyte progenitor recruitment, Mol. Cell. Endocrinol., 2017, 445, 95-108.

40 M. Rosenwald, A. Perdikari, T. Rülicke and C. Wolfrum, Bidirectional interconversion of brite and white adipocytes, Nat. Cell Biol., 2013, 15, 659-667.

41 S. Kajimura, B. M. Spiegelman and P. Seale, Brown and beige fat: Physiological roles beyond heat generation, Cell Metab., 2015, 22, 546-559.

42 J. Himms-Hagen, A. Melnyk, M. C. Zingaretti, E. Ceresi, G. Barbatelli and S. Cinti, Multilocular fat cells in WAT of CL-316243-treated rats derive directly from white adipocytes, Am. J. Physiol.: Cell Physiol., 2000, 279, C670-C681.

43 S. Cinti, Transdifferentiation properties of adipocytes in the adipose organ, Am. J. Physiol.: Endocrinol. Metab., 2009, 297, e977-e986.

44 Y. H. Lee, A. P. Petkova, A. A. Konkar and J. G. Granneman, Cellular origins of cold-induced brown adipocytes in adult mice, FASEB J., 2015, 29, 286-299.

45 A. Kaisanlahti and T. Glumoff, Browning of white fat: agents and implications for beige adipose tissue to type 2 diabetes, J. Physiol. Biochem., 2019, 75, 1-10.

46 H. C. Roh, L. T. Y. Tsai, M. Shao, D. Tenen, Y. Shen, M. Kumari, A. Lyubetskaya, C. Jacobs, B. Dawes, R. K. Gupta and E. D. Rosen, Warming Induces Significant Reprogramming of Beige, but Not Brown, Adipocyte Cellular Identity, Cell Metab., 2018, 27, 1121-1137.

47 A. Fenzl and F. W. Kiefer, Brown adipose tissue and thermogenesis, Horm. Mol. Biol. Clin. Invest., 2014, 19, 25-37.

48 I. Murano, C. M. Zingaretti and S. Cinti, The adipose organ of Sv129 mice contains a prevalence of brown adipocytes 
and shows plasticity after cold exposure, Adipocytes, 2005, 1, 121-130.

49 D. B. Hausman, J. B. Fine, K. Tagra, S. S. Fleming, R. J. Martin and M. DiGirolamo, Regional fat pad growth and cellularity in obese zucker rats: Modulation by caloric restriction, Obes. Res., 2003, 11, 674-682.

50 E. D. Rosen and O. A. MacDougald, Adipocyte differentiation from the inside out, Nat. Rev. Mol. Cell Biol., 2006, 7, 885-896.

51 C. Uder, S. Brückner, S. Winkler, H. M. Tautenhahn and B. Christ, Mammalian MSC from selected species: Features and applications, Cytometry, Part A, 2018, 93, 32-49.

52 C. J. Morris, D. Aeschbach and F. A. Scheer, Circadian system, sleep and endocrinology, Mol. Cell. Endocrinol., 2012, 349, 91-104.

53 K. L. Gamble, R. Berry, S. J. Frank and M. E. Young, Circadian clock control of endocrine factors, Nat. Rev. Endocrinol., 2014, 10, 466-475.

54 V. C. Khanh, A. F. Zulkifli, C. Tokunaga, T. Yamashita, Y. Hiramatsu and O. Ohneda, Aging impairs beige adipocyte differentiation of mesenchymal stem cells via the reduced expression of Sirtuin 1, Biochem. Biophys. Res. Commun., 2018, 500, 682-690.

55 D. F. Pisani, M. Djedaini, G. E. Beranger, C. Elabd, M. Scheideler, G. Ailhaud and E. Z. Amri, Differentiation of human adipose-derived stem cells into "brite" (brown-inwhite) adipocytes, Front. Endocrinol., 2011, 2, 87.

56 A. M. Fayyad, A. A. Khan, S. H. Abdallah, S. S. Alomran, K. Bajou and M. N. K. Khattak, Rosiglitazone enhances browning adipocytes in association with MAPK and PI3-K pathways during the differentiation of telomerase-transformed mesenchymal stromal cells into adipocytes, Int. J. Mol. Sci., 2019, 20, 1618.

57 B. Cannon and J. Nedergaard, Brown Adipose Tissue: Function and Physiological Significance, Physiol. Rev., 2004, 84, 277-359.

58 A. Bartelt and J. Heeren, Adipose tissue browning and metabolic health, Nat. Rev. Endocrinol., 2014, 10, 24-36.

59 K. Velickovic, H. A. Lugo Leija, I. Bloor, J. Law, H. Sacks, M. Symonds and V. Sottile, Low temperature exposure induces browning of bone marrow stem cell derived adipocytes in vitro, Sci. Rep., 2018, 8, 4974.

60 A. Rashnonejad, G. Ercan, C. Gunduz, A. Akdemir and Y. O. Tiftikcioglu, Comparative analysis of human UCB and adipose tissue derived mesenchymal stem cells for their differentiation potential into brown and white adipocytes, Mol. Biol. Rep., 2018, 45, 233-244.

61 R. Xue, M. D. Lynes, J. M. Dreyfuss, F. Shamsi, T. J. Schulz, H. Zhang, T. L. Huang, K. L. Townsend, Y. Li, H. Takahashi, L. S. Weiner, A. P. White, M. S. Lynes, L. L. Rubin, L. J. Goodyear, A. M. Cypess and Y. H. Tseng, Clonal analyses and gene profiling identify genetic biomarkers of the thermogenic potential of human brown and white preadipocytes, Nat. Med., 2015, 21, 760-768.

62 A. L. Carey, C. Vorlander, M. Reddy-Luthmoodoo, A. K. Natoli, M. F. Formosa, D. A. Bertovic, M. J. Anderson,
S. J. Duffy and B. A. Kingwell, Reduced UCP-1 content in in vitro differentiated beige/brite adipocytes derived from preadipocytes of human subcutaneous white adipose tissues in obesity, PLoS One, 2014, 9, e91997.

63 F. Luchetti, B. Canonico, D. Bartolini, M. Arcangeletti, S. Ciffolilli, G. Murdolo, M. Piroddi, S. Papa, R. J. Reiter and F. Galli, Melatonin regulates mesenchymal stem cell differentiation: A review, J. Pineal Res., 2014, 56, 382-397.

64 P. Puigserver and B. M. Spiegelman, Peroxisome proliferator-activated receptor- $\gamma$ coactivator $1 \alpha$ (PGC-1 $\alpha)$ : Transcriptional coactivator and metabolic regulator, Endocr. Rev., 2003, 24, 78-90.

65 M. Uldry, W. Yang, J. St-Pierre, J. Lin, P. Seale and B. M. Spiegelman, Complementary action of the PGC-1 coactivators in mitochondrial biogenesis and brown fat differentiation, Cell Metab., 2006, 3, 333-341.

66 C. Tiraby, G. Tavernier, C. Lefort, D. Larrouy, F. Bouillaud, D. Ricquier and D. Langin, Acquirement of brown fat cell features by human white adipocytes, J. Biol. Chem., 2003, 278, 33370-33376.

67 H. Artsi, I. Gurt, M. El-Haj, R. Müller, G. A. Kuhn, G. ben Shalom, E. Cohen-Kfir, E. Abramowitz, L. Kandel, O. Safran and R. Dresner-Pollak, Sirt1 promotes a thermogenic gene program in bone marrow adipocytes: From mice to (Wo) men, Front. Endocrinology, 2019, 10, 126.

68 G. Corbi, V. Conti, G. Russomanno, G. Longobardi, G. Furgi, A. Filippelli and N. Ferrara, Adrenergic signaling and oxidative stress: A role for sirtuins?, Front. Physiol., 2013, 4, 324.

69 Y. H. Tseng, E. Kokkotou, T. J. Schulz, T. L. Huang, J. N. Winnay, C. M. Taniguchi, T. T. Tran, R. Suzuki, D. O. Espinoza, Y. Yamamoto, M. J. Ahrens, A. T. Dudley, A. W. Norris, R. N. Kulkarni and C. R. Kahn, New role of bone morphogenetic protein 7 in brown adipogenesis and energy expenditure, Nature, 2008, 454, 1000-1004.

70 P. L. Huang, Y. C. Chen, L. H. Chen, C. C. Juan, H. H. Ku, S. T. Wang, S. H. Chiou, G. Y. Chiou, C. W. Chi, C. C. Hsu, H. C. Lee, L. K. Chen and C. L. Kao, PGC- $1 \alpha$ mediates differentiation of mesenchymal stem cells to brown adipose cells, J. Atheroscler. Thromb., 2011, 18, 966-980.

71 J. Wu, P. Boström, L. M. Sparks, L. Ye, J. H. Choi, A. H. Giang, M. Khandekar, K. A. Virtanen, P. Nuutila, G. Schaart, K. Huang, H. Tu, W. D. van Marken Lichtenbelt, J. Hoeks, S. Enerbäck, P. Schrauwen and B. M. Spiegelman, Beige adipocytes are a distinct type of thermogenic fat cell in mouse and human, Cell, 2012, 150, 366-376.

72 H. Ohno, K. Shinoda, B. M. Spiegelman and S. Kajimura, PPAR $\gamma$ agonists induce a white-to-brown fat conversion through stabilization of PRDM16 protein, Cell Metab., 2012, 15, 395-404.

73 D. Zhang, S. He, Q. Wang, S. Pu, Z. Zhou and Q. Wu, Impact of Aging on the Characterization of Brown and White Adipose Tissue-Derived Stem Cells in Mice, Cells Tissues Organs, 2020, 1-11.

74 S. Su, A. R. Guntur, D. C. Nguyen, S. S. Fakory, C. C. Doucette, C. Leech, H. Lotana, M. Kelley, J. Kohli, 
J. Martino, S. Sims-Lucas, L. Liaw, C. Vary, C. J. Rosen and A. C. Brown, A Renewable Source of Human Beige Adipocytes for Development of Therapies to Treat Metabolic Syndrome, Cell Rep., 2018, 25, 3215-3228.

75 F. Silva, C. Elabd, V. Vargas, V. Grinstein and A. Patel, Characterization of Human Brown Adipose Derived Stem Cells, Cytotherapy, 2016, 18, S79.

76 L. Vishvanath, K. A. Macpherson, C. Hepler, Q. A. Wang, M. Shao, S. B. Spurgin, M. Y. Wang, C. M. Kusminski, T. S. Morley and R. K. Gupta, Pdgfr $\beta$ + mural preadipocytes contribute to adipocyte hyperplasia induced by high-fatdiet feeding and prolonged cold exposure in adult mice, Cell Metab., 2016, 23, 350-359.

77 W. Wang and P. Seale, Control of brown and beige fat development, Nat. Rev. Mol. Cell Biol., 2016, 17, 691-702.
78 J. S. Kim, Y. H. Jung, H. J. Lee, C. W. Chae, G. E. Choi, J. R. Lim, S. Y. Kim, J. E. Lee and H. J. Han, Melatonin activates $\mathrm{ABCA} 1$ via the BiP/NRF1 pathway to suppress highcholesterol-induced apoptosis of mesenchymal stem cells, Stem Cell Res. Ther., 2021, 12, 1-14.

79 S.-A. Mostafavi, S. Akhondzadeh, M. R. Mohammadi, A.-A. Keshtkar, S. Hosseini, M. R. Eshraghian, T. A. Motlagh, R. Alipour and S. A. Keshavarz, Role of Melatonin in Body Weight: A Systematic Review and MetaAnalysis, Curr. Pharm. Des., 2017, 23, 3445-3452.

80 A. V. Garcia Ramirez, D. R. Filho and I. J. Zotarelli Filho, Meta-analysis and Approach of the Real Impact of Anorexigenic Drugs in the Obesity in Humans: The Last Five Years of the Randomized Studies, Current Diabetes Reviews, 2019, 16, 750-758. 